\title{
SUSTENTABILIDADE SOCIAL DO TURISMO NO MUNICÍPIO DE MACHADINHO-RS
}

Luana Teixeira de Lacerda Mestra Programa de Pós Graduação em Turismo e Hospitalidade Universidade de Caxias do Sul Rio Grande do Sul / RS. Brasil. luteixeiralacerda@gmail.com

Marlei Salete Mecca Doutora Programa de Pós Graduação em Turismo e Hospitalidade Universidade de Caxias do Sul. Rio Grande do Sul / RS. Brasil.

\section{Resumo} msmecca@ucs.br

Objetivo do estudo: Analisar como se apresenta a sustentabilidade social promovida pelo turismo no parque termal no município de Machadinho - RS, por meio da aplicação de uma adaptação do Sistema de Indicadores de Sustentabilidade para Atividade Turística - SISDTur (Hanai, 2009).

Metodologia/abordagem: Metodologia de natureza exploratória e descritiva, de abordagem quantitativa, na modalidade de estudo de caso, fazendo uso de levantamento, por meio da aplicação de questionários como técnica de coleta de dados.

Originalidade/Relevância: $\mathrm{O}$ estudo apresenta dados inéditos discorrendo sobre a sustentabilidade social do turismo, expondo informações quanto ao seu desenvolvimento em destinações do interior do Rio Grande do Sul pouco pesquisadas sobre esse viés, principalmente no que tange as águas termais como principal atrativo turístico.

Principais resultados: Os resultados obtidos sinalizam para o potencial sustentável das atividades existentes, onde os respondentes percebem os impactos positivos da atividade turística, não tendo nenhum indicador considerado insustentável. Porém, a existência de indicadores parcialmente insustentáveis, exige um posicionamento estratégico da gestão, visando que a destinação se desenvolva de modo que o efeito multiplicador do turismo seja sentido por toda a comunidade.

Contribuições teóricas/metodológicas: Apresenta dados referentes à um tema pouco estudado na academia, contribuindo para as discussões em torno da temática, fornecendo informações relevantes para a compreensão e desenvolvimento do turismo sustentável.

Contribuições sociais: Propõem uma abordagem a partir da percepção do trade turístico local, concebendo informações que possam auxiliar na gestão do turismo da destinação, e de demais localidades que buscam desenvolver o turismo em seus territórios.

Palavras-chave: Turismo. Sustentabilidade social. Gestão do turismo. Machadinho - RS.

Cite como

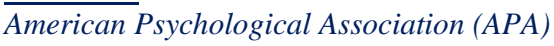

Lacerda, L. T. de, \& Mecca, M. S. (set./dez. 2020). Sustentabilidade social do turismo no município de Machadinho-RS. PODIUM Sport, Leisure and Tourism Review, São Paulo, 9(3), 462-496. https://doi.org/10.5585/podium.v9i3.16225. 


\section{SOCIAL SUSTAINABILITY OF TOURISM IN THE MUNICIPALITY OF MACHADINHO- RS}

Objective of the study: To analyze how the social sustainability promoted by tourism in the thermal park in the municipality of Machadinho - RS, through the application of an adaptation of the System of Sustainability Indicators for Tourism Activity - SISDTur (Hanai, 2009).

Methodology: Methodology of an exploratory and descriptive nature, with a quantitative approach, in the form of case study, making use of a survey, through the application of questionnaires as a data collection technique.

Originality/Relevance: The study presents unpublished data discussing the social sustainability of tourism, exposing information regarding its development in destinations in the interior of Rio Grande do Sul not much researched on this bias, especially with regard to thermal waters as the main tourist attraction.

Main results: The results obtained signal the sustainable potential of existing activities, where respondents perceive the positive impacts of tourism activity, with no indicator considered unsustainable. However, the existence of partially unsustainable indicators, requires a strategic management positioning, aiming that the destination develops so that the multiplier effect of tourism is felt by the entire community.

Theoretical/methodological contributions: It presents data related to a little studied topic in the academy, contributing to the discussions around the thematic, providing relevant information for the understanding and development of sustainable tourism.

Social contributions: They propose an approach based on the perception of the local tourist trade, conceiving information that can assist in the tourism management of the destination and of other locations that seek to develop tourism in their territories.

Keywords: Tourism, social sustainability, tourism management, Machadinho - RS.

\section{SOSTENIBILIDAD SOCIAL DEL TURISMO EN EL MUNICIPIO DE MACHADINHO-RS}

Objetivo del estudio: Analizar cómo se presenta la sostenibilidad social promovida por el turismo en el parque termal del municipio de Machadinho - RS, por meio de la aplicación de una adaptación del Sistema de Indicadores de Sostenibilidad de la Actividad Turística - SISDTur (Hanai, 2009).

Metodología/enfoque: Metodología de naturaleza exploratoria y descriptiva, abordaje cuantitativa, en la modalidad de estudio de caso, haciendo uso de encuesta, por medio de la aplicación de cuestionarios como técnica de colecta de datos.

Originalidad/Relevancia: El estudio presenta datos inéditos discurriendo sobre la sostenibilidad social del turismo, exponiendo informaciones en cuanto a su desarrollo en destinaciones del interior de Rio Grande do Sul poco investigadas sobre ese sesgo, principalmente en lo que tange las aguas termales como principal atractivo turístico.

Principales resultados: Los resultados obtenidos señalan el potencial sostenible de las actividades existentes, donde los encuestados perciben los impactos positivos de la actividad turística, sin ningún indicador insostenible. Sin embargo, la existencia de indicadores que presentan resultados parcialmente 
insostenibles, requiere de un posicionamiento estratégico de la gestión, con vistas a que el destino se desarrolle para que el efecto multiplicador del turismo sea sentido por toda la comunidad.

Contribuciones teóricas/metodológicas: La investigación presenta datos referentes a un tema poco estudiado en la academia, contribuyendo a las discusiones en torno al tema, brindando informaciones relevantes para la comprensión y desarrollo del turismo sostenible.

Contribuciones sociales: Proponen un enfoque basado en la percepción del trade turístico local, diseñando informaciones que puedan ayudar en la gestión del turismo de destino y de otras localidades que buscan desarrollar el turismo en sus territorios.

Palabras clave: Turismo. Sostenibilidad social. Gestión turística. Machadinho - RS.

\section{Introdução}

O fenômeno turístico demanda de inúmeras atividades para que se concretize, estabelecendo relação com diversos setores, causando interferências diretas e indiretas nas destinações onde se desenvolve (Lage \& Milone, 1998). O ser humano encontra, por meio do turismo, possibilidades de expansão seja pelo divertimento, bem estar físico ou pelo encontro com outras pessoas, podendo trocar conhecimentos e culturas (Barretto, 1991). A efemeridade que permeia as emoções e relações na sociedade contemporânea exige do turismo articulações ágeis e estratégicas no intuito de que ele possa crescer e se fortalecer.

O "novo" turista, cada dia mais curioso, busca por cenários diferenciados que possam satisfazer suas necessidades, prezando pelo bem-estar e a liberdade em suas decisões, orientados por uma consciência ambiental e sociocultural que vem se desenvolvendo, levandoos a optarem por empresas e atrativos responsáveis (Campos, Mendes \& Silva, 2006). Nesse cenário, adquirem visibilidade, destinações e empreendimentos turísticos que proporcionem experiências singulares, com segurança, contato com a natureza e culturas exóticas e originais. Com base nessas informações, municípios com potencialidades turísticas, descobrem no turismo uma fonte para mudar suas realidades, aquecendo suas economias.

De acordo com Beni (1999, p. 97), o turismo pode ser considerado como uma alternativa para a evolução socioeconômica das destinações tendo em vista "[...] seus importantes efeitos econômicos, sociais, ambientais, políticos e culturais[...]". Quando organizado e planejado torna-se um “[...] poderoso instrumento de aceleração ou complementação do processo de desenvolvimento.” (p. 97). O autor esclarece ainda que o “[...] planejamento permite orientar, racionalizar e acelerar esse processo de mudança social, que é complexo, porque, além de 
realizar ações voltadas à solução de problemas, também é preciso mudar estruturas e modos de atuar.” (Beni, 2006, p. 7). E a participação da comunidade na formulação do plano de turismo é peça fundamental proporcionando uma visão ampla das realidades existentes e inserindo-os no desenvolvimento da atividade (Nugraheni, Priyambodo, Sutikno \& Kusworo, 2019; Lin \& Simmons, 2017; Teixeira, Vieira, \& Mayr, 2019).

A partir desse envolvimento os residentes poderão tomar conhecimento dos processos e possibilidade do turismo para a inserção de seus negócios ou para o fomento do crescimento de empreendedores que venham a criar novos empreendimentos e atrativos dentro do segmento. Essa movimentação do setor gerará um fluxo de renda não somente local, mas nas regiões onde as regiões turísticas estão inseridas.

Nesse cenário de inúmeras possibilidades de interferências tanto positivas quanto negativas, as atividades do turismo devem ser pensadas tendo como fundamentos os princípios da sustentabilidade, a partir de um planejamento claro, estruturado e inclusivo que busque um desenvolvimento saudável e benéfico, com potencial crescimento (Santos, Costa \& Santos, 2020). Tem-se, portanto, a necessidade da apropriação dos princípios da sustentabilidade, de modo a favorecer o planejamento e a gestão das atividades turísticas (Moleiro, 2020; Ferreira, Bertolini \& Brandalise, 2019; Prihanti, Priyambodo, Sutikno \& Kusworo, 2020). A partir disto este artigo buscou responder a seguinte questão de pesquisa: como se apresenta a sustentabilidade social e econômica promovida pelo turismo no parque termal no município de Machadinho - RS? Para tanto utilizou-se uma adaptação do Sistema de Indicadores de Sustentabilidade para Atividade Turística - SISDTur (Hanai, 2009), tendo como objetivo apresentar os dados obtidos referente a dimensão social.

A metodologia utilizada é de natureza exploratória e descritiva, quanto a abordagem classificada como quantitativa, na modalidade de estudo de caso, fazendo uso de levantamento, por meio da aplicação de questionários como técnica de coleta de dados. As informações foram obtidas mediante a participação de representantes do trade turístico de Machadinho - RS: Poder Público, Associação de Desenvolvimento Turístico de Machadinho - ADTM -, Câmara de Dirigentes Lojista de Machadinho - RS e sociedade civil.

Apesar de muitos estudos se debruçarem sobre o tema sustentabilidade no turismo, a dimensão social da sustentabilidade turística ainda carece de pesquisas aprofundadas na academia (Dempsey, Bramley, Power \& Brown, 2011; Nugraheni et al., 2020), principalmente no que tange à análise de destinações turísticas do interior do estado do Rio Grande do Sul que 
não pertencem a região turística Uva e Vinho ou região das Hortênsias. Da mesma forma, a partir de estudos de Lacerda e Mecca (2018) foi diagnosticado um baixo número de estudos no Brasil referentes ao uso das águas termais para o turismo e, dentre eles, nenhum que relacione o desenvolvimento social sustentável nas regiões onde estas são o principal atrativo. Além disso, amplia as pesquisas em torno de um conceito que, se adotado, possibilita um desenvolvimento com benefícios para toda a cadeia envolvida. Ainda, por fazer uso de uma adaptação do SISDTur (Hanai, 2009) propõem uma abordagem a partir da percepção do trade turístico local, concebendo informações que possam auxiliar na gestão do turismo da destinação em questão, quanto de demais localidades que buscam desenvolver o turismo em seus territórios.

O presente artigo encontra-se estruturado em cinco partes. A primeira é realizada a introdução na qual se desenvolve uma contextualização do assunto, é feita a apresentação do objetivo central da pesquisa e algumas das justificativas quanto à elaboração do estudo. $\mathrm{Na}$ segunda parte foi construído um referencial teórico o qual serviu de embasamento para o desenvolvimento do trabalho.

A terceira parte apresenta os procedimentos metodológicos que estruturaram esta pesquisa. A análise dos dados coletados em campo compõe a quarta parte do estudo e, por fim, a quinta parte apresenta as considerações finais quanto à pesquisa.

\section{Referencial teórico}

\subsection{Turismo contemporâneo}

O turismo, como fenômeno de constante mutação, vem passando por constantes transformações ao longo do tempo, provocando inúmeras mudanças tanto nas destinações quanto nos viajantes (Dias, 2008; Ruschmann, 2000).

Usadas como atrativo turístico há séculos (Smith \& Puczkó, 2017), as águas termais também passaram por um processo de ressignificação de seu uso. As fontes termais motivaram viagens e o fluxo de turistas fomentou o surgimento de grandes e importantes destinações. $\mathrm{O}$ turismo de saúde, apesar de na época de seu surgimento não haver devida análise científica das águas (Rejowski, Yasoshima, Stigliano \& Silveira, 2002), converteu os espaços termais em ambientes de busca pela cura e também de prazer e descanso. 
Espelhando-se na Europa, em 1818 foi criada no Brasil a primeira estância termal em Santa Catarina (Quintela, 2004). Aos poucos, a partir de estudos científicos, novas destinações foram nascendo como afirma Quintela (2004, p. 252): “Tudo começou com a descoberta das análises químicas, ainda na primeira metade do século, e com a edificação de alguns estabelecimentos termais (Caldas do Cubatão, Caxambu e Poços de Caldas) na segunda metade do mesmo século.”. O ambiente termal moderno, diferenciando-se do modelo tradicional utilizado nos séculos anteriores, não se dedica exclusivamente a atividades para a melhoria e/ou manutenção da saúde física, mas sim, para o bem-estar e o lazer (Rocha, 2011; Naraindas \& Bastos, 2011). É encarado como um lugar de descanso, de socialização e de prazer fazendo uso das águas termais associadas a recursos turísticos, agregando valor ao produto turístico local (Araújo, 2009).

Porém, é necessário salientar, de acordo com Powis e O'Leary (2009), que o desenvolvimento do turismo de saúde e bem-estar precisa ser planejado de maneira sustentável considerando a comunidade receptora e inserindo-a nas atividades e na construção do setor. Os benefícios devem ser sentidos pela população local e não apenas desfrutado pelos turistas (Bushell \& Sheldon, 2009; Quintela, Costa \& Correia, 2017; Quintela, Correia \& Antunes, 2011; Stevens, Azara \& Michopoulou, 2018).

A partir dessas questões a discussão da sustentabilidade no turismo torna-se necessária para que a atividade se desenvolva e impacte de maneira positiva na vida dos envolvidos, gerando proveitos que sejam distribuídos de maneira homogênea.

Diante dessa situação, em 1987, a Comissão Mundial sobre o Meio Ambiente e o Desenvolvimento, da ONU, elaborou o Relatório Brundtland, onde é proposta a adoção do desenvolvimento de maneira sustentável (Novaes, 2013; Aurelio Sobrinho, 2016). Lemos (2005, p. 75) conceitua o turismo sustentável como sendo "Um processo de transformação no qual a exploração de recursos, a direção dos investimentos, a orientação da evolução tecnológica e a mudança institucional se harmonizam e reforçam o potencial presente e futuro, a fim de atender às necessidades e aspirações humanas". Ainda, de acordo com Ashton (2005, p. 108), o termo sustentabilidade suscita uma reflexão quanto a existência de um “[...] desenvolvimento econômico e social contínuo, sem prejuízo do ambiente e dos recursos naturais, de cuja qualidade depende a continuidade da atividade humana e do desenvolvimento". 
Considerando essas informações, depreende-se que a sustentabilidade deve ser uma condição do turismo e não um tipo de turismo (Dorin, 2013), no qual a comunidade esteja integrada e participativa, possibilitando mudanças sociais e econômicas positivas.

Por usufruir de variados recursos para a formação do produto turístico, o turismo tem a obrigação e também oferece a possibilidade de agir em benefício da comunidade, preservando os patrimônios (materiais e imateriais), além de oportunizar melhorias na qualidade de vida das comunidades (Unwto \& United Nations Global Compact Network Spain, 2016). Portanto, para que haja um desenvolvimento, de fato, sustentável, de acordo com a Unites Nations Environment Programme - UNEP e a World Tourism Organization - UNWTO (2005) é necessário observar três pilares: a) dimensão econômica: atividades econômicas viáveis e de longo prazo com geração de renda e distribuição em diferentes camadas sociais; b) dimensão ambiental: uso racional dos recursos naturais, protegendo a biodiversidade e minimizando a degradação do meio ambiente; c) dimensão sociocultural: respeito aos direitos humanos, oportunidades para todos, melhoria da qualidade de vida, preservação das tradições e do patrimônio material e imaterial. Apesar de o conceito de sustentabilidade ser relacionado, principalmente, às questões ambientais, passou-se a considerar a cultura, sociedade e a economia como elementos indispensáveis para a existência do que se considera uma real sustentabilidade (Beni, 2020).

O tema sustentabilidade social refere-se as necessidades ligadas ao bem-estar pessoal dos indivíduos. Sachs (2007, p. 288) salienta que a dimensão social “[...] aparece como uma preocupação relacionada à organização interna de cada sociedade humana e da comunidade mundial de nações cada vez mais interdependentes", a qual prima por valores como democracia e igualdade social, buscando reduzir a distância entre padrões sociais e melhorar a qualidade de vida da população (Sachs, 2007; 1993; Beni, 2006; Jorge, 2015; Nugraheni et al., 2019). De acordo com Vianna (2011) é possível encontrar pesquisas que apresentam o tema "qualidade de vida" com diversos delineamentos e a partir de múltiplos aspectos pois envolve, também, fatores subjetivos como a percepção individual dos envolvidos em uma determinada sociedade.

Porém, é necessário atentar para que essa qualidade de vida esteja acessível a toda a população (Oliveira, 2002), tornando os sistemas sociais adequados para toda a diversidade humana, indiferentemente da raça, língua, nacionalidade, gênero, orientação sexual, deficiência e outros atributos (Sassaki, 2009). 
Cabe assinalar que, a apesar das oportunidades proporcionadas pelo turismo, muitas comunidades receptoras são afetadas negativamente pelo turismo mal planejado. Sem um planejamento adequado, os prejuízos ocasionados por determinadas atividades turísticas podem suscitar na população local uma aversão ao turismo impedindo sua expansão (Beni, 2020; Milano, Cheer \& Novelli, 2018). Nisso cabe a gestão turística avaliar as necessidades da demanda (sejam residentes ou turistas) e meios de atendê-la, além de pensar estratégias para que o turista respeite a comunidade receptora e usufrua de forma racional e educada dos atrativos que visitar (Milano et al., 2018). De acordo com Renk (2013, p. 69), a ética deve conduzir as relações entre a população local e os visitantes pois "O respeito à diferença cultural e a possibilidade de aprendizado com as diferentes práticas sociais são essenciais na relação do turista com outras culturas". Diante disso, a infraestrutura básica deve satisfazer, primeiramente, as necessidades dos residentes, porém, não pode perder sua qualidade ao receber a demanda turística, promovendo uma experiência interessante e atrativa.

Todas essas afirmações evidenciam a relevância do planejamento para o desenvolvimento sustentável do turismo. Face a essa necessidade, na sequência serão examinados os elementos básicos ao planejamento de destinações turísticas.

\subsection{Planejamento das destinações turísticas e mensuração das atividades}

Autores como Lage e Milone (1998, p. 37) sinalizam que o turismo apresenta, além da possibilidade de benefícios aos envolvidos, potencial para "[...] alterar ou distorcer padrões culturais no seu processo de crescimento". O planejamento é uma importante etapa para a existência saudável da atividade (Costa, Melo \& Pimenta, 2014). Nesse sentido, de acordo com Lemos (2005, p. 24) o planejamento das atividades “[...] surge como vital para integrar, agregar e dar consciência aos valores turísticos". Diante disso, tomamos aqui o conceito de planejamento estabelecido por Molina (1997, p. 37), o qual pressupõem “[...]a planificação consiste em estabelecer um curso de ação que conduza ao alcance da situação desejada mediante um esforço constante, coerente, ordenado, sistemático e generalizado.”

A partir de uma análise minuciosa das necessidades dos residentes e dos visitantes, são estabelecidos os recursos disponíveis, o orçamento a ser investido, as estratégias para engajar e envolver a comunidade receptora e as ações para desenvolver o setor (Ruschmann, 2000; Jegdić, Škrbić \& Milošević, 2013; Ashton, 2005). O Plano Nacional do Turismo 2018-2022 (Brasil, 2015b, p. 71) evidencia que "O turismo, para ter garantia de sucesso como atividade 
econômica, depende de um planejamento realizado de forma integrada e participativa e que ofereça os meios adequados para sua implementação e administração.”. Além disso o planejamento precisa ser multidisciplinar, considerando os públicos envolvidos e as realidades nas quais encontram-se inseridos (Jegdić et al., 2013), devendo ser o estado o responsável principal por “[...] zelar pelo planejamento e pela legislação necessária ao desenvolvimento da infraestrutura básica que proporcionará o bem-estar da população residente e dos turistas" (Ruschmann, 2000, p. 84).

Ainda, a gestão turística deve "[...] buscar soluções que possibilitem uma melhoria no que tange à infraestrutura, igualdade regional, capacitação dos recursos humanos, e equilíbrio na concentração de renda das populações envolvidas na atividade.” (Lage \& Milone, 1998, p. 204), em um processo contínuo de acompanhamento das ações propostas, adequando-as quando necessário.

Todo esse processo demanda qualificação multidisciplinar da mão e obra, realizando-se por duas vias: “A primeira é a formação profissional, que se espraia nos cursos, pesquisas [...]. A segunda é a via da certificação, que, por meio de comprovação de conhecimentos e habilidades exercidas, explicita ao mercado a qualidade dos profissionais" (Brasil, 2015a). Porém, Lage e Milone (1998, p. 34) relatam que muitos destinos turísticos não possuem “"...] pessoal experiente que possa assumir a responsabilidade do estímulo e da coordenação do desenvolvimento turístico" levando os gestores a importarem mão de obra capacitada. Essa realidade deve ser alterada por programas de qualificação dos trabalhadores locais, proporcionando que a renda gerada permaneça na localidade. Goeldner, Ritchie e McIntosh (2002) destacam que o planejamento deve tomar como base o bem-estar dos envolvidos, considerando que o turismo é capaz de auxiliar na resolução e/ou amenização de problemas sociais, salientando que "Políticas sólidas de desenvolvimento podem gerar um setor turístico crescente, junto com a preservação dos recursos naturais e culturais" (Goeldner, Ritchie \& McIntosh, 2002, p. 338).

Para compreender a situação do setor local é necessário utilizar indicadores que apontem a sustentabilidade existente e suas carências fornecendo, assim, dados para a elaboração de estratégias (Santos et al., 2020). Conforme Butler (1999) não há sustentabilidade sem indicadores para certificar sua existência seu estado. A norma NBR 16534 (Associação Brasileira de Normas Técnicas, 2016, p. 2) conceitua indicadores como sendo uma "[...] medida repetida através do tempo, que permite avaliar o cumprimento dos objetivos, os resultados de 
uma determinada atividade ou o sucesso de uma organização". Os indicadores fornecem informações que possibilitam a avaliação das mudanças, servindo para detectar problemas e elaborar estratégias focadas no futuro (UNWTO, 2003) necessitando de ações de monitoramento.

Para esta pesquisa optou-se pela utilização do conjunto de indicadores elaborados por Hanai (2009), contando com a participação da sociedade local: o Sistema de Indicadores de Sustentabilidade do Desenvolvimento do Turismo - SISDTur, o qual possui uma metodologia que reúne indicadores distribuídos em 6 dimensões (ambiental, cultural, econômica, social, turística e institucional) com o intuito de contribuir para o processo de desenvolvimento do turismo, tendo como base os princípios da sustentabilidade e o envolvimento da comunidade. Nesta pesquisa são abordados apenas as informações relativas à dimensão social, para a qual foram realizadas adequações no instrumento de coleta, visando adaptá-lo à realidade local.

\section{Procedimentos metodológicos}

Este trabalho foi elaborado com base em uma metodologia de natureza bibliográfica e descritiva. Quanto à abordagem pode ser classificado como quantitativo, a partir de um estudo de caso, fazendo uso de levantamento como técnica de coleta de dados.

De acordo com Fonseca (2002, p. 32) a pesquisa bibliográfica “[...] é feita a partir do levantamento de referências teóricas já analisadas, e publicadas por meios escritos e eletrônicos, como livros, artigos científicos, páginas de web sites.”, possibilitando conhecer os materiais disponíveis na área de estudo e identificar as teorias existentes (Gil, 2002). Complementarmente a pesquisa descritiva realiza o processo de observação, registro, análise dos fatos e ou fenômenos, porém, sem a manipulação dos mesmos (Cervo \& Bervian, 2002).

A abordagem quantitativa mantém sua base na objetividade. Fonseca (2002, p. 20) evidencia que "A pesquisa quantitativa recorre à linguagem matemática para descrever as causas de um fenômeno, as relações entre variáveis, etc", fazendo uso de técnicas estatísticas. Sua principal característica é a tradução das informações coletadas em números para posteriormente classificar e analisar esses dados (Souza, Fialho \& Otani, 2007).

Buscando "[...] conhecer em profundidade o como e o porquê de uma determinada situação que se supõe ser única em muitos aspectos, procurando descobrir o que há nela de mais essencial e característico.” (Fonseca, 2002, p. 33), utiliza-se o estudo de caso. Essa técnica proporciona maior detalhamento e profundidade de conhecimento (Gil, 2002). 
A partir dessas definições foi utilizada a técnica conhecida como levantamento para a coleta de informações, a qual "Consiste na coleta de dados referentes a uma dada população a partir de uma amostra selecionada [...]. As conclusões obtidas com a amostra são projetadas para o universo.” (Dencker, 1998, p. 127). De acordo com Rigsby (1987, pp. 49-50) “[...] os investigadores que realizam pesquisas de levantamento tipicamente coletam seus dados a partir de respostas verbais a questões predeterminadas feitas à maioria ou a todos os sujeitos de pesquisa.”. Utilizou-se questionários como instrumentos de coleta, tendo como finalidade “[...] obter, de maneira sistemática e ordenada, informações sobre as variáveis que intervêm em uma investigação em relação à uma população ou amostra determinada.” (Dencker, 1998, p. 146).

O questionário (Anexo) foi aplicado a uma amostra do grupo de agentes do turismo no município de Machadinho, tendo sido estruturado em duas partes: a primeira com questões para identificação do perfil do participante e a segunda com afirmativas relacionadas à dimensões social das atividades turísticas de Machadinho - RS. O questionário foi enviado de forma impressa e por meio digital, e os respondentes, após o preenchimento, retornaram o mesmo.

\subsection{O município de machadinho}

Machadinho, município distante aproximadamente $400 \mathrm{~km}$ da capital Porto Alegre possui, segundo dados do senso 2010 (Ibge, 2017) população estimada de 5.510 pessoas, e têm como base econômica, principalmente a agropecuária.

$\mathrm{O}$ destino do município, em direção à exploração do turismo, tem como marco a construção da Usina Hidrelétrica Machadinho, no ano de 1998, construída próximo à destinação, provocando o alagamento de entregou ao município um parque termal como forma de ressarcimento pelos danos ambientais e perdas sociais e econômicas (Biscaro, 2017). A partir da abertura do Thermas Machadinho, complexo de $98.000 \mathrm{~m}^{2}$, com águas que vertem do solo à $45^{\circ} \mathrm{C}$, Machadinho passou a investir no setor turístico, transformando em destinação turística. A escolha do Município para a pesquisa ocorreu tendo em vista o aumento acelerado da demanda de turistas no complexo das águas termais "Thermas Machadinho". O aumento da demanda são constatações dos residentes e da iniciativa pública e privada e também pela governança do destino.

Além de piscinas abertas, o Thermas Machadinho (Figura 1) conta com um complexo de inverno, com piscinas cobertas, possibilitando o recebimento de visitantes em todas as 
estações, além de brinquedos, empreendimentos comerciais, serviços de gastronomia e espaços de lazer com churrasqueiras distribuídos pelo parque (Rio Grande do Sul, 2019).

A construção do Thermas Machadinho desencadeou novos processos de geração de renda no município, motivando o investimento no desenvolvimento da atividade turística, abrindo portas para a exploração de outros recursos presentes no município, com o intuito de aumentar a atratividade da destinação. Atualmente, além do Thermas Machadinho, o município conta com outros oito atrativos turísticos, que fazem uso de recursos ambientais e culturais, de acordo com Associação de Desenvolvimento Turístico de Machadinho - ADTM (2018).

Esse cenário atraiu, não apenas turistas, mas, investidores externos e propiciou também um ambiente favorável ao empreendedorismo dos residentes locais e, com isso, a abertura de novos postos de trabalho e a geração de renda.

Além do surgimento dos atrativos turísticos, outras mudanças foram percebidas no município, como é possível observar a partir do crescimento do Índice de desenvolvimento humano dos municípios (IDHM), utilizado para avaliar o bem-estar da população analisando indicadores como educação, esperança de vida, natalidade e economia dos municípios (Souza, 2008). De 2000 a 2010 o IDHM de Machadinho obteve um crescimento de mais de $21 \%$, passando de 0,571 para 0,692. A dimensão do IDHM que demonstrou maior crescimento foi a educação $(45,7 \%)$ e a renda um crescimento de $(19,69 \%$ (Atlas do Desenvolvimento Humano do Brasil, 2019).

Ainda, com relação a educação local, os dados do Atlas do Desenvolvimento Humano no Brasil (2019) demonstram um aumento do número de crianças e adolescentes com acesso à educação. Em 2010, o percentual de crianças entre 5 e 6 anos frequentando a escola era de $83,07 \%$, já 90,47\% era o percentual de crianças com idades entre 11 e 13 anos frequentando os anos finais do ensino fundamental. Quanto aos jovens de 15 a 17 anos com ensino fundamental completo a soma é de $64,71 \%$. Com ensino médio completo, o percentual de jovens entre 18 e 20 anos era de apenas $48,03 \%$.

Paralelamente novas vagas de trabalho formal, foram abertas. Em 2000, no setor do comércio, o número de pessoas com carteira assinada totalizava 50 empregados, enquanto que no setor de serviços eram 54 empregados, de acordo com o Ministério do Trabalho e Emprego (Brasil, 2019c). No ano de 2010, é possível observar o aumento no número de vagas, sendo que no comércio totalizam 152, ao passo que os serviços contavam com 74 postos de trabalho. De 2010 a 2017 houve um crescimento de 19,73\% nas vagas do comércio totalizando 182, 
enquanto que no setor de serviços, o aumento foi de 68,11\% passando à 232 vagas ocupadas (Brasil, 2019c). Como consequência a renda per capita foi alterada, passando de $\mathrm{R} \$ 323,26 \mathrm{em}$ 2000 para $\mathrm{R} \$ 669,60$ em 2010.

Esses números evidenciam as mudanças ocorridas no município a partir de 2010 e demonstram o potencial do turismo para o desenvolvimento das destinações, a partir de um planejamento estruturado adequadamente.

\subsection{Instrumento de coleta de dados e amostra}

Para a obter as informações necessárias optou-se por investigar uma amostra da população pesquisada, obtida a partir da subdivisão da população em grupos (Stevenson, 1981). Nessa amostra estão inseridos agentes componentes do setor turístico de Machadinho-RS, compreendendo 48 respondentes. Os grupos são compostos por 41 associados à Associação de Desenvolvimento Turístico de Machadinho (ADTM) e Câmara de Dirigentes Lojistas de Machadinho (CDL Machadinho) - 12 representantes de meios de hospedagem, cinco representantes de empresas de serviços de alimentação e 24 representantes do comércio -; quatro representantes do Poder Público Municipal - o Prefeito, o Secretário Municipal do Turismo, a Secretária Municipal da Administração e a Secretária Municipal da Educação e Cultura; representando a sociedade civil o presidente da CDL Machadinho, o presidente da ADTM e o presidente do Sindicato dos Trabalhadores Rurais de Machadinho. A aplicação dos questionários se deu pela pesquisadora presencialmente e via formulário online.

Quanto ao instrumento proposto por Hanai (2009), para adequá-lo à realidade local, equipe de pesquisa e orçamento disponível, foram necessárias adaptações, direcionando-o para a obtenção dos dados referentes a dimensão social.

Para suprir as necessidades da pesquisa foram realizadas alterações quanto aos indicadores e parâmetros de medição, sendo que, para cada indicador foram criadas afirmativas correspondentes que viabilizaram a coleta das informações dos respondentes e possibilitaram a utilização da escala de Likert (Likert, 1932). No Quadro 1 são apresentados os descritores, objetivos, indicadores e afirmativas utilizadas. Os descritores e indicadores foram destacados com diferentes cores para identificar as adaptações, sendo: descritores, objetivos e indicadores na cor verde os propostos por Hanai (2009); os na cor laranja, adaptados de Hanai (2009); e indicadores na cor azul, elaborados pelas autoras (2019). 
Quadro 1 - Dimensão social

\begin{tabular}{|c|c|c|c|}
\hline \multicolumn{4}{|c|}{ Dimensåo Social } \\
\hline Descritor & Objetivo & Indicadores & Indicador/afirmativa \\
\hline \multirow{6}{*}{$\begin{array}{l}\text { Inserção de } \\
\text { residentes } \\
\text { locais (origem } \\
\text { local) no setor } \\
\text { turístico }\end{array}$} & \multirow{6}{*}{$\begin{array}{l}\text { Identificar o grau de insercão de } \\
\text { residentes locais no setor turístico e as } \\
\text { iniciativas de capacitaçắo turística. }\end{array}$} & \multirow{3}{*}{$\begin{array}{l}\text { Residentes locais empregados no } \\
\text { estabelecimento turístico }\end{array}$} & $\begin{array}{l}\text { Há um percentual significativo de residentes locais empregados } \\
\text { nos estabelecimentos do destino turistioo. }\end{array}$ \\
\hline & & & \begin{tabular}{|l|} 
A maioria dos funcionários é de origem local. \\
\end{tabular} \\
\hline & & & Há vagas de emprego inclusivas em atividades turísticas. \\
\hline & & \begin{tabular}{|l|} 
Proprietários e empresários de \\
estabelecimentos turisticos de origem local
\end{tabular} & $\begin{array}{l}\text { Dentre proprietarios e empresários turísticos, a maioria é de } \\
\text { origem local. }\end{array}$ \\
\hline & & $\begin{array}{l}\text { Iniciativas de capacitaçăo e treinamento } \\
\text { profissional aos funcionários residentes } \\
\text { locais num periodo. }\end{array}$ & $\begin{array}{l}\text { Existem iniciativas de capacitação e treinamento profissional } \\
\text { para os residentes locais. }\end{array}$ \\
\hline & & $\begin{array}{l}\text { Funcionánios residentes locais com } \\
\text { capacitacão em turismo. }\end{array}$ & $\begin{array}{l}\text { Dentre os funcionários que sejam residentes locais há uma } \\
\text { parcela com capacitacăo em turismo. }\end{array}$ \\
\hline $\begin{array}{l}\text { Nivel de } \\
\text { empregabilidade } \\
\text { em turismo }\end{array}$ & $\begin{array}{l}\text { Identificar a evolução de empregos de } \\
\text { turismo em suas distintas concepçöes }\end{array}$ & Empregos focos e temporários de turismo. & $\begin{array}{l}\text { O número de empregos fixos em turismo é maior que o número } \\
\text { de empregos temporários no setor. }\end{array}$ \\
\hline \multirow{4}{*}{$\begin{array}{l}\text { Comunicação } \\
\text { turística local }\end{array}$} & \multirow{3}{*}{$\begin{array}{l}\text { Identificar a eficácia da comunicação local } \\
\text { sobre as atividades do setor turístico }\end{array}$} & \multirow{3}{*}{$\begin{array}{l}\text { Comunicạ̧ão sobre o calendário de } \\
\text { eventos }\end{array}$} & $\begin{array}{l}\text { Os moradores obtém com facilidade as informaçóes sobre as } \\
\text { atividades turisticas. }\end{array}$ \\
\hline & & & $\begin{array}{l}\text { A divulgaçáo dos atrativos turístico do município é suficiente para } \\
\text { atrair visitantes. }\end{array}$ \\
\hline & & & $\begin{array}{l}\text { Existem locais onde os turistas podem obter informapóes básicas } \\
\text { sobre turismo e infraestrutura local. }\end{array}$ \\
\hline & $\begin{array}{l}\text { Idențíficar iniciativas de comunicação para } \\
\text { a sustentabilidade } \\
\end{array}$ & $\begin{array}{l}\text { Comunicacáo pública para } 0 \\
\text { desenvolvimento sustentável do turismo } \\
\end{array}$ & $\begin{array}{l}\text { Existem iniciativas de comunicaçâo a respeito da } \\
\text { sustentabilidade económica e social da atividade turistica local. } \\
\end{array}$ \\
\hline \multirow{4}{*}{$\begin{array}{l}\text { Participaçāo da } \\
\text { comunidade } \\
\text { local }\end{array}$} & \multirow{4}{*}{$\begin{array}{l}\text { Identificar a existência de projetos sociais } \\
\text { envolvendo os residentes locais }\end{array}$} & \multirow{2}{*}{$\begin{array}{l}\text { Programas sociais de engajamento dos } \\
\text { residentes no turismo local }\end{array}$} & $\begin{array}{l}\text { Existem programas e/ou projetos sociais que envolvam os } \\
\text { residentes locais visando engajá-los no desenvolvimento do } \\
\text { turismo. }\end{array}$ \\
\hline & & & $\begin{array}{l}\begin{array}{l}\text { Residentes e funcionários de estabelecimentos possuem } \\
\text { informaçöes básicas para esclarecer os turistas. }\end{array} \\
\end{array}$ \\
\hline & & \multirow{2}{*}{$\begin{array}{l}\text { Existência de projetos sociais para } \\
\text { melhoria da qualidade de vida local }\end{array}$} & $\begin{array}{l}\text { Existem programas elou projetos voltados às melhorias sociais } \\
\text { dos residentes. }\end{array}$ \\
\hline & & & $\begin{array}{l}\text { Existem projetos voltados à sustentabilidade económica e social } \\
\text { do turismo local. }\end{array}$ \\
\hline \multirow{2}{*}{$\begin{array}{l}\text { Estrutura de } \\
\text { saúde }\end{array}$} & \multirow{2}{*}{$\begin{array}{l}\text { Identificar a existência de estrutura de } \\
\text { saúde básica }\end{array}$} & \multirow{2}{*}{$\begin{array}{l}\text { Existência de estrutura de saúde básica } \\
\text { para atendimento aos residentes }\end{array}$} & $\begin{array}{l}\text { Os servicos básicos de saúde sáo suficientes para atender a } \\
\text { populaçąo local. }\end{array}$ \\
\hline & & & $\begin{array}{l}\text { A estrutura dos servicos básicos de saúde é suficiente para } \\
\text { atender as necessidades dos visitantes. }\end{array}$ \\
\hline \multirow{2}{*}{$\begin{array}{l}\text { Ensino escolar } \\
\text { básico }\end{array}$} & \multirow{2}{*}{$\begin{array}{l}\text { Identificar a existência de vagas nas } \\
\text { escolas }\end{array}$} & Vagas nas escolas públicas & $\begin{array}{l}\text { Todas as crianças e jovens com idade escolar tếm acesso à } \\
\text { educacăo. }\end{array}$ \\
\hline & & \begin{tabular}{|l} 
Qualidade do ensino público local \\
\end{tabular} & A qualidade do ensino básico local é satisfatória \\
\hline \multirow{2}{*}{$\begin{array}{l}\text { Segurança } \\
\text { pública }\end{array}$} & \multirow[b]{2}{*}{ Identificar a qualidade da segurança local } & \begin{tabular}{|l|} 
Seguranca local \\
\end{tabular} & Os residentes sentem-se seguros ao transitar pelo município. \\
\hline & & $\begin{array}{l}\text { Satisfacáo quanto a segurança para } \\
\text { residentes e visitantes }\end{array}$ & $\begin{array}{l}\text { A segurança pública é satisfatória para atender residentes e } \\
\text { turistas. }\end{array}$ \\
\hline \multirow{5}{*}{$\begin{array}{l}\text { Infraestrutura } \\
\text { habitacional }\end{array}$} & \multirow{5}{*}{$\begin{array}{l}\text { Identificar a existência de infraestrutura } \\
\text { habitacional }\end{array}$} & $\begin{array}{l}\text { Existéncia de infraestrutura habitacional } \\
\text { (água, esgoto, iluminacão, pavimentacăo) }\end{array}$ & $\begin{array}{l}\text { Existe infraestrutura habitacional (água, esgoto, eletricidade, } \\
\text { pavimentacăo) em todo municipio. }\end{array}$ \\
\hline & & \multirow[t]{2}{*}{ Existência de transporte coletivo } & O transporte coletivo é suficiente para atender a demanda. \\
\hline & & & Há transporte coletivo para a visitaçáo dos atrativos turísticos. \\
\hline & & \multirow{2}{*}{$\begin{array}{l}\text { Contentamento com a estrutura do } \\
\text { município após o turismo }\end{array}$} & $\begin{array}{l}\text { O turismo proporcionou melhorias na qualidade estrutural do } \\
\text { municipio. }\end{array}$ \\
\hline & & & \begin{tabular}{|l|} 
Parte dos recursos advindos da atividade tuństica são investidos \\
em obras públicas (água, esgoto, eletricidade, pavimentação).
\end{tabular} \\
\hline $\begin{array}{l}\text { Presenca de } \\
\text { visitantes }\end{array}$ & $\begin{array}{l}\text { Identificar o contentamento quanto à } \\
\text { presenca de visitantes }\end{array}$ & $\begin{array}{l}\begin{array}{l}\text { Contentamento com a presença dos } \\
\text { visitantes }\end{array} \\
\end{array}$ & A presença dos visitantes năo causa desconforto aos residentes. \\
\hline Custo de vida & $\begin{array}{l}\text { Identificar a elevaçáo do custo de vida } \\
\text { após o inicio da exploraçâo do turismo } \\
\text { local }\end{array}$ & Gastos relativos ao custo de vida & $\begin{array}{l}\text { Näo houve elevaçäo no custo de vida dos moradores após o } \\
\text { inicio da exploraçáo do turismo local. }\end{array}$ \\
\hline
\end{tabular}

Fonte: Adaptado de Hanai (2009).

O instrumento foi estruturado com sete questões para identificação do perfil do respondente e, 27 afirmativas às quais estavam associadas respostas de múltipla escolha, relacionadas ao grau de concordância do respondente, possibilitando o uso da Escala de Likert (1932) (Quadro 2). A partir do uso dessa escala é possível obter o grau de concordância ou discordância sobre uma determinada afirmação, atribuindo-lhe um número que reflete o posicionamento dos respondentes, sendo, em geral composta por cinco níveis de concordância, divididos em: discordo totalmente, discordo parcialmente, neutro (nem concordo, nem discordo), concordo parcialmente e concordo totalmente (Hanai, 2009). 
Quadro 2 - Escala de Likert de 5 pontos

\begin{tabular}{|l|l|}
\hline \multicolumn{1}{|c|}{ Escala } & \multicolumn{1}{|c|}{ Classificaçäo } \\
\hline 1 & Discordo totalmente \\
\hline 2 & Discordo parcialmente \\
\hline 3 & Neutro \\
\hline 4 & Concordo parcialmente \\
\hline 5 & Concordo totalmente \\
\hline
\end{tabular}

Fonte: Elaborado pelas autoras (2019).

Os graus de concordância atribuídos à cada afirmação pelos participantes da pesquisa, foram analisados considerando a média, o desvio padrão, o coeficiente de variação e a moda, tendo como ferramentas o software estatístico Statical Package for the Social Science (SPSS) e a planilha eletrônica Microsoft Office Excel, usados de maneira complementar, para tabulação e tratamento dos dados obtidos. Para a análise da sustentabilidade de cada grupo utilizou-se como critério a moda (Quadro 3) pois, de acordo com Muniz (2015, p. 273), “[...] o elemento que ocorre com maior frequência, isto é, o elemento mais comum", sendo escolhida por melhor adequar-se a pequenas amostras.

A partir da obtenção dos resultados individuais dos grupos, para a análise final dos indicadores, houve a necessidade do estabelecimento de critérios, os quais foram organizados tendo em vista os estudos de Santos (2013): Se o indicador for considerado insustentável pelos três grupos, ele é parcialmente insustentável; b) Se parcialmente sustentável pelos três grupos ele é parcialmente insustentável; c) Se sustentável pelos três grupos ele é sustentável; d) Se sustentável e/ou potencialmente por dois grupos, ele é potencialmente sustentável; e) Se potencialmente sustentável por três grupos, ele é potencialmente sustentável; f) Se intermediário/neutro por dois ou mais grupos; ou respostas distintas entre os grupos intermediário/neutro, potencialmente sustentável/sustentável e parcialmente insustentável/insustentável - ele é de sustentabilidade intermediária.

Quadro 3 - Moda / sustentabilidade

\begin{tabular}{|l|l|}
\hline \multicolumn{1}{|c|}{ Moda } & \multicolumn{1}{|c|}{ Nível de sustentabilidade } \\
\hline Moda 1 & Insustentável \\
\hline Moda 2 & Parcialmente insustentável \\
\hline Moda 3 & Sustentabilidade intermediária/neutra \\
\hline Moda 4 & Potencialmente sustentável \\
\hline Moda 5 & Sustentável \\
\hline
\end{tabular}

Fonte: Elaborado pela autora (2019).

Considerando esses critérios, tem-se o indicador apontando insustentável como inaceitável; quando parcialmente insustentável, o indicador apresenta desempenho indesejável; 
quando neutro, exprime um desempenho neutro ou, possivelmente, em fase de transição; quando considerado potencialmente sustentável, representa um desempenho aceitável e o desempenho desejável é expresso por meio dos indicadores que forem considerados sustentáveis (Prescott-Allen, 2001).

A partir do cumprimento dessas etapas foi possível analisar a sustentabilidade social do turismo no município de Machadinho-RS, sendo os resultados de cada indicador debatidos no capítulo seguinte.

\section{Análise dos dados coletados}

\subsection{Perfil dos respondentes}

Dentre os respondentes, a maioria é do sexo feminino (Tabela 1) e no quesito idade, $68,8 \%$ do total de respondentes pertence as gerações X e Y, nascidos entre as décadas de 1960 e 1980, com idades entre 32 anos e 59 anos.

Quanto a naturalidade, dos 48 participantes, 28 nasceram no município de Machadinho e apenas quatro imigraram de outros estados. Dentre os respondentes que não são naturais de Machadinho, 11 pessoas fixaram moradia no município nos últimos 15 anos, após o início da exploração do turismo, e um dos respondentes possui a empresa na destinação, porém reside em cidade vizinha.

Em concordância com os dados do IDHM, apresentado pelo Atlas do Desenvolvimento Humano no Brasil (2019), no quesito escolaridade, verifica-se um aumento nos níveis de escolaridade, sendo que $87 \%$ dos respondentes possui ensino médio (42 pessoas) e, dentre estes, $31,3 \%$ concluíram o ensino superior e 10,4\% são pós-graduados. O comércio é o único setor entre os respondentes que possui representantes com renda bruta individual mensal inferior a $\mathrm{R} \$ 954,01$ (Tabela 9). Dentre os 24 respondentes do setor comércio, 41,66\% possuem renda individual bruta mensal entre $\mathrm{R} \$ 954,01$ e $\mathrm{R} \$ 1.908$, outros $29,16 \%$ têm renda individual mensal entre $\mathrm{R} \$ 2.862,01$ e $\mathrm{R} \$ 4.770,01$ e apenas $8,33 \%$ com mais de $\mathrm{R} \$ 4.770,01$. No setor de hospedagem 41,66\% dos respondentes têm renda individual mensal entre R \$954,01 e R \$ 1.908, $25 \%$ com renda entre $\mathrm{R} \$ 2.862,01$ e $\mathrm{R} \$ 4.770,01$ e $25 \%$ entre $\mathrm{R}$ \$2.862,01 e $\mathrm{R} \$ 4.770,01$. Já nos empreendimentos de serviços de alimentação $60 \%$ dos respondentes apresentam renda individual mensal entre $\mathrm{R} \$ 2.862,01$ e $\mathrm{R} \$ 4.770,01$ e $40 \%$ entre $\mathrm{R} \$ 954,01$ e $\mathrm{R} \$ 2.862,01$. O 
setor de hospedagem é, entre os respondentes, o que possui o maior número de integrantes, por grupo, com renda individual bruta mensal superior a $\mathrm{R} \$ 4.770,01$.

\subsection{Dimensão social do turismo}

Os indicadores pertencentes à dimensão social foram elaborados com o intuito de analisar a sustentabilidade social promovida pelo turismo local. No total essa dimensão é composta por dez descritores e 28 indicadores que são apresentados no Quadro 4.

Quadro 4 - Indicadores da dimensão social

\begin{tabular}{|c|c|c|c|c|c|c|c|c|c|c|c|}
\hline \multicolumn{2}{|r|}{ Dimensão Social } & \multicolumn{3}{|c|}{$\begin{array}{l}\text { Hospedagem/ } \\
\text { Alimentaçăo }\end{array}$} & \multicolumn{3}{|c|}{ Poder Público } & \multicolumn{3}{|c|}{ Sociedade civil } & \multirow[t]{2}{*}{ Resultado geral } \\
\hline \multirow{7}{*}{$\begin{array}{l}\text { Inserção de residentes } \\
\text { locais (origem local) no } \\
\text { setor turistico }\end{array}$} & Indicador & Média & $\mathrm{CV}$ & Moda & Média & CV & Moda & Média & CV & Moda & \\
\hline & $\begin{array}{l}\text { Há um percentual significativo de residentes locais } \\
\text { empregados nos estabelecimentos do destino turistico. }\end{array}$ & 3,85 & 0,2 & 4,0 & 4,25 & 0,1 & 4,0 & 3,66 & 0,4 & 2,0 & $\begin{array}{l}\begin{array}{l}\text { Potencialmente } \\
\text { sustentável }\end{array} \\
\end{array}$ \\
\hline & A maioria dos funcionários é de origem local. & 3,85 & 0,3 & 4,0 & 4,5 & 0,1 & 4,0 & 3,66 & 0,4 & 2,0 & $\begin{array}{l}\text { Potencialmente } \\
\text { sustentável }\end{array}$ \\
\hline & Há vagas de emprego inclusivas em atividades turisticas. & 3,9 & 0,3 & 4,0 & 4 & 0,4 & 5,0 & 4,66 & 0,1 & 5,0 & $\begin{array}{l}\text { Potencialmente } \\
\text { sustentável }\end{array}$ \\
\hline & $\begin{array}{l}\text { Dentre proprietários e empresários turísticos, a maioria é } \\
\text { de origem local. }\end{array}$ & 3,07 & 0,4 & 4,0 & 2,75 & 0,5 & 4,0 & 3,66 & 0,4 & 2,0 & \begin{tabular}{|l|}
$\begin{array}{l}\text { Potencialmente } \\
\text { sustentável }\end{array}$ \\
\end{tabular} \\
\hline & $\begin{array}{l}\begin{array}{l}\text { Existem iniciativas de capacitaçăo e treinamento } \\
\text { profissional para os residentes locais. }\end{array} \\
\end{array}$ & 2,63 & 0,5 & 3,0 & 3,0 & 0,5 & 4,0 & 4,0 & 0,3 & 3,0 & Intermediária \\
\hline & $\begin{array}{l}\text { Dentre os funcionários que sejam residentes locais há uma } \\
\text { parcela com capacitaçầo em turismo. }\end{array}$ & 2,95 & 0,4 & 3,0 & 3,0 & 0,3 & 3,0 & 4,0 & 0,3 & 3,0 & Intermediária \\
\hline $\begin{array}{lr}\begin{array}{l}\text { Nivel } \\
\text { empregabilidade }\end{array} & \text { de } \\
\text { turismo } & \end{array}$ & $\begin{array}{l}\text { O número de empregos fixos em turismo é maior que o } \\
\text { número de empregos temporários no setor. }\end{array}$ & 3,73 & 0,3 & 4,0 & 3,75 & 0,4 & 5,0 & 3,66 & 0,4 & 2,0 & \begin{tabular}{|l} 
Potencialmente \\
sustentável
\end{tabular} \\
\hline \multirow{4}{*}{$\begin{array}{l}\text { Comunicação turística } \\
\text { local }\end{array}$} & $\begin{array}{l}\text { Os moradores obtếm com facilidade as informaç̧ōes sobre } \\
\text { as atividades turisticas. }\end{array}$ & 3,29 & 0,4 & 2,0 & 4,0 & 0,4 & 5,0 & 4,0 & 0 & 4,0 & $\begin{array}{l}\text { Potencialmente } \\
\text { sustentável }\end{array}$ \\
\hline & $\begin{array}{l}\text { A divulgaçăa dos atrativos turistico do municipio é } \\
\text { suficiente para atrair visitantes. }\end{array}$ & 2,65 & 0,4 & 2,0 & 3,5 & 0,5 & 4,0 & 3,0 & 0,3 & 2,0 & $\begin{array}{l}\text { Parcialmente } \\
\text { insustentável }\end{array}$ \\
\hline & $\begin{array}{l}\begin{array}{l}\text { Existem locais onde os turistas podem obter informaçōes } \\
\text { básicas sobre turismo e infraestrutura local. }\end{array} \\
\end{array}$ & 3,07 & 0,4 & 4,0 & 3,5 & 0,5 & 4,0 & 3,33 & 0,3 & 4,0 & $\begin{array}{l}\begin{array}{l}\text { Potencialmente } \\
\text { sustentável }\end{array} \\
\end{array}$ \\
\hline & $\begin{array}{l}\text { Existem iniciativas de comunicaçăa a respeito da } \\
\text { sustentabilidade econômica e social da atividade turistica } \\
\text { local. }\end{array}$ & 2,92 & 0,4 & 3,0 & 3,25 & 0,5 & 4,0 & 3,66 & 0,3 & 3,0 & Intermediária \\
\hline \multirow{4}{*}{$\begin{array}{l}\text { Participaçäo da } \\
\text { comunidade local }\end{array}$} & \begin{tabular}{|l|} 
Existem programas e/ou projetos sociais que \\
envolvam os residentes locais visando engajá-los no \\
desenvolvimento do turismo.
\end{tabular} & 2,61 & 0,5 & 2,0 & 3,5 & 0,4 & 2,0 & 3,0 & $|0,7|$ & 1,0 & $\begin{array}{l}\text { Parcialmente } \\
\text { insustentável }\end{array}$ \\
\hline & $\begin{array}{l}\text { Residentes e funcionários de estabelecimentos } \\
\text { possuem informaçőes básicas para esclarecer os } \\
\text { turistas. }\end{array}$ & 3,43 & 0,3 & 4,0 & 3.25 & 0,5 & 4,0 & 3,66 & 0,4 & 2,0 & $\begin{array}{l}\text { Potencialmente } \\
\text { sustentável }\end{array}$ \\
\hline & $\begin{array}{l}\begin{array}{l}\text { Existem programas e/ou projetos voltados as } \\
\text { melhorias sociais dos residentes. }\end{array} \\
\end{array}$ & 2,78 & 0,4 & 3,0 & 3,0 & 0,6 & 1,0 & 3,33 & 0,6 & 1,0 & $\begin{array}{l}\text { Parcialmente } \\
\text { insustentável }\end{array}$ \\
\hline & \begin{tabular}{|l|}
$\begin{array}{l}\text { Existem projetos voltados à sustentabilidade } \\
\text { econômica e social do turismo local. }\end{array}$ \\
\end{tabular} & 2,63 & 0,4 & 2,0 & 3,75 & 0,5 & 5,0 & 3,66 & 0,6 & 5,0 & $\begin{array}{l}\begin{array}{l}\text { Potencialmente } \\
\text { sustentável }\end{array} \\
\end{array}$ \\
\hline \multirow[b]{2}{*}{ Estrutura de saúde } & $\begin{array}{l}\text { Os serviços básicos de saúde são suficientes para } \\
\text { atender a população local. }\end{array}$ & 2,92 & 0,4 & 4,0 & 3,75 & 0,3 & 4,0 & 4,33 & 0,1 & 4,0 & \begin{tabular}{|l} 
Potencialmente \\
sustentável
\end{tabular} \\
\hline & $\begin{array}{l}\text { A estrutura dos serviços básicos de saúde é } \\
\text { suficiente para atender as necessidades dos } \\
\text { visitantes. }\end{array}$ & 2,97 & 0,4 & 4,0 & 3,5 & 0,4 & 2,0 & 4,33 & 0,1 & 4,0 & $\begin{array}{l}\text { Potencialmente } \\
\text { sustentável }\end{array}$ \\
\hline \multirow{2}{*}{$\begin{array}{l}\text { Ensino } \\
\text { básico }\end{array}$} & $\begin{array}{l}\text { Todas as crianças e jovens com idade escolar têm } \\
\text { acesso à educação. }\end{array}$ & 4,73 & 0,1 & 5,0 & 4,75 & 0,1 & 5,0 & 5,0 & 0 & 5,0 & Sustentável \\
\hline & A qualidade do ensino básico local é satisfatória & 3,7 & 0,3 & 4,0 & 5,0 & 0 & 5,0 & 5,0 & 0 & 5,0 & $\begin{array}{l}\text { Potencialmente } \\
\text { sustentável }\end{array}$ \\
\hline \multirow{2}{*}{ Segurança pública } & $\begin{array}{l}\text { Os residentes sentem-se seguros ao transitar pelo } \\
\text { município. }\end{array}$ & 4,24 & 0,2 & 5,0 & 4,0 & 0,4 & 5,0 & 4,66 & 0,1 & 5,0 & Sustentável \\
\hline & $\begin{array}{l}\text { A segurança pública é satisfatória para atender } \\
\text { residentes e turistas. }\end{array}$ & 3,46 & 0,4 & 4,0 & 4,0 & 0,4 & 5,0 & 4,33 & 0,1 & 4,0 & \begin{tabular}{|l}
$\begin{array}{l}\text { Potencialmente } \\
\text { sustentável }\end{array}$ \\
\end{tabular} \\
\hline \multirow{5}{*}{$\begin{array}{l}\text { Infraestrutura } \\
\text { habitacional }\end{array}$} & $\begin{array}{l}\text { Existe infraestrutura habitacional (água, esgoto, } \\
\text { eletricidade, pavimentação) em todo municipio. }\end{array}$ & 3,31 & 0,3 & 4,0 & 3,75 & 0,3 & 4,0 & 3,0 & 0,6 & 4,0 & $\begin{array}{l}\text { Potencialmente } \\
\text { sustentável }\end{array}$ \\
\hline & $\begin{array}{l}\text { transporte coletivo é suficiente para atender a } \\
\text { demanda. }\end{array}$ & 3,02 & 0,4 & 3,0 & 3,25 & 0,4 & 3,0 & 3,0 & 0,3 & 2,0 & Intermediária \\
\hline & $\begin{array}{l}\begin{array}{l}\text { Há transporte coletivo para a visitação dos atrativos } \\
\text { turísticos. }\end{array} \\
\end{array}$ & 3,53 & 0,4 & 4,0 & 4,0 & 0,4 & 5,0 & 4,33 & 0,1 & 4,0 & $\begin{array}{l}\text { Potencialmente } \\
\text { sustentável }\end{array}$ \\
\hline & $\begin{array}{l}\text { turismo proporcionou melhorias na qualidade } \\
\text { estrutural do municipio. }\end{array}$ & 4,53 & 0,6 & 5,0 & 4,75 & 0.1 & 5,0 & 4,66 & 0,1 & 5,0 & Sustentável \\
\hline & $\begin{array}{l}\text { Parte dos recursos advindos da atividade turística } \\
\text { são investidos em obras públicas (água, esgoto, } \\
\text { eletricidade, pavimentação). }\end{array}$ & 2,19 & 0,5 & 1,0 & 2,75 & 0,5 & 4,0 & 3,3 & 0,3 & 4,0 & $\begin{array}{l}\text { Potencialmente } \\
\text { sustentável }\end{array}$ \\
\hline $\begin{array}{l}\text { Presença } \\
\text { visitantes }\end{array}$ & $\begin{array}{l}\text { A presença dos visitantes não causa desconforto aos } \\
\text { residentes. }\end{array}$ & 4,39 & 0,2 & 5,0 & 3,5 & 0,5 & 2,0 & 4,66 & 0,1 & 5,0 & \begin{tabular}{|l} 
Potencialmente \\
sustentável
\end{tabular} \\
\hline Custo de vida & $\begin{array}{l}\text { Não houve elevacção no custo de vida dos moradores } \\
\text { após o início da exploração do turismo local. }\end{array}$ & 2,56 & 0,5 & 1,0 & 4,0 & 0,6 & 5,0 & 3,66 & 0,4 & 2,0 & $\begin{array}{l}\text { Parcialmente } \\
\text { insustentável }\end{array}$ \\
\hline
\end{tabular}

Fonte: Elaborado pelas autoras (2019). 


\subsubsection{Inserção de residentes locais no setor turístico}

A partir das informações coletadas com os respondentes, os três primeiros indicadores sobre a inserção dos residentes locais no setor turístico são considerados como potencialmente sustentáveis pelos setores do comércio, hospedagem e serviços de alimentação, porém há uma discrepância se comparada às informações da sociedade civil pois, de acordo com os representantes participantes da pesquisa, os indicadores mencionados foram considerados parcialmente insustentável, demonstrando haver possibilidades de maior inserção dos residentes enquanto proprietários ou mão de obra nas atividades turísticas.

Quanto às questões de capacitação, foram consideradas de sustentabilidade intermediária, apresentando potencial para melhorias. Convém ressaltar que não há no município instituição de ensino técnico ou superior. Os estudantes necessitam buscar capacitação em outras localidades ou cursos à distância, principalmente. Essa situação segue inversa ao que foi estabelecido pela Política Nacional de Turismo - Lei No 11.771 - (Brasil, 2008, não paginado), na qual ficou definido a criação do Comitê Interministerial de Facilitação Turística que, entre outros objetivos, “[...] visa incentivar a formação, a capacitação profissional, a qualificação, o treinamento e a reciclagem de mão-de-obra para o setor turístico e sua colocação no mercado de trabalho".

Evidenciando a necessidade, conforme estudos de Aguiar e Bahl (2006), Dencker (2004) e do Ministério do Turismo (Brasil, 2020), o desenvolvimento da atividade turística está, diretamente, associado ao desenvolvimento profissional dos envolvidos e a insuficiência de mão de obra qualificada tem dificultado o desenvolvimento do setor turístico pois, para as ações de atendimento ao turista, de acordo com os autores, o ser humano jamais poderá ser substituído.

\section{$\underline{4.2 .3 ~ N i ́ v e l ~ d e ~ e m p r e g a b i l i d a d e ~ e m ~ t u r i s m o ~}$}

O indicador da empregabilidade foi considerado potencialmente sustentável, considerando que, para os respondentes, a maioria das vagas de emprego existentes no setor turístico local é permanente. Porém, para os representantes da sociedade civil o indicador se apresentou parcialmente insustentável, apontando que o número de vagas fixas em alguns seguimentos é superado pelas vagas temporárias. 
Há de se considerar que o atrativo turístico principal de Machadinho-RS é o um parque termal que, apesar de possuir águas quentes, tende a ter sua demanda aumentada nos meses de verão o que, possivelmente, acarreta na necessidade de abertura de novas vagas de trabalho para atender a demanda durante esse período.

\subsubsection{Comunicação turística local}

De acordo com os respondentes, os turistas encontram alguns locais onde possam obter informações básicas sobre os estabelecimentos e atrativos do município, o que torna o indicador potencialmente sustentável. Porém, cabe ressaltar que o município não possui Centro de Atendimento ao Turista - CAT - ou não há identificação em sites turísticos locais. Quanto as informações aos moradores o indicador apresentou-se, também, como potencialmente sustentável. Esses resultados possibilitam depreender que, para muitos residentes, as informações são não compreensíveis ou os canais pelos quais são transmitidas não estão acessíveis a todos.

Quanto a comunicação para a divulgação do turismo local, o indicador apresentou-se sustentável apenas para o poder público, enquanto os demais respondentes consideram o indicador parcialmente insustentável, possivelmente por escassez ou por uma comunicação ineficaz no processo de divulgação dos atrativos locais.

O Plano Nacional de Turismo 2018-2022 - PNT 2018-2022 - (Brasil, 2015b) destaca que uma das maiores carências no que tange a promoção do turismo brasileiro é a insuficiência de informações de qualidade sobre a oferta turista, sendo imprescindível ampliar a utilização da promoção e da comunicação digital das destinações gerando um relacionamento para com residentes, turistas e a imprensa.

Além das informações de divulgação dos atrativos é oportuno fazer uso da comunicação para desenvolver uma consciência voltada ao consumo responsável do turismo e estimular a adoção de práticas sustentáveis (Brasil, 2015b; Tolkes, 2018). Nesse sentido, o indicador utilizado para coletar as informações dos respondentes quanto a comunicação de práticas sustentáveis no município foi considerado de sustentabilidade intermediária, possibilitando induzir que, se são adotadas práticas ou discursos para a sustentabilidade, estas não são comunicadas de forma assertiva. 


\subsubsection{Participação da comunidade local}

Sem a participação da comunidade local não há sustentabilidade (Ranauro, 2004; Ko, 2005; Irving, Bursztyn, Sancho \& Melo, 2005) pois, de acordo com a UNWTO (2003, p. 95) é a partir do envolvimento dos residentes que eles “[...] entenderão o turismo, terão maiores condições de lidar com esse novo desenvolvimento em sua área e de participar dos seus benefícios [...]". Apesar disso, a realidade do município, exposta pelo resultado dos indicadores insustentáveis, é de falta de incentivos à participação e engajamento, resultado que, possivelmente, pode estar ligado as questões comunicacionais, discutidas no item 2.4.3

O resultado do indicador que busca avaliar a existência de programas ou projetos que envolvam os residentes visando engajá-los no desenvolvimento do turismo, é considerado parcialmente insustentável, apontando as carências existentes quanto às iniciativas de envolver e comprometer a população com a atividade turística. Concomitantemente o indicador relacionado a existência de programas e/ou projetos voltados às melhorias sociais dos residentes apresentou-se parcialmente insustentável. Para os representantes do comércio, hospedagem e serviços de alimentação, o indicador é considerado, em sua maioria, como intermediário. Porém, os outros dois grupos acreditam que este indicador é insustentável. Salienta-se que o resultado intermediário/neutro, exprime uma opinião neutra. Esse dado deixa em alerta o indicador, expondo a insuficiência nas ações que visem proporcionar benefícios sociais a comunidade. Quanto ao indicador que buscou coletar dados quanto ao conhecimento básico sobre o turismo local que os residentes e funcionários de estabelecimentos possuem, o indicador apresentou-se potencialmente sustentável.

Ainda, o indicador sobre a existência de projetos voltados à sustentabilidade econômica e social do turismo local apresenta-se potencialmente sustentável. Porém, para o comércio, meios de hospedagem e serviços de alimentação, o indicador é parcialmente insustentável. Considerando que o indicador que buscou informações sobre as iniciativas de comunicação a respeito da sustentabilidade turística ter sido considerado intermediário, verifica-se aqui uma inconstância ou um desencontro entre a existência das ações e a forma de divulgá-las sendo consequência de informações acessíveis a poucos indivíduos ou a falta de propostas e projetos voltados à sustentabilidade. 


\subsubsection{Estrutura de saúde}

Os indicadores deste descritor apresentam-se potencialmente sustentáveis aos representantes do comércio, meios de hospedagem, serviços de alimentação e sociedade civil. O grupo do poder público discorda, considerando a estrutura para atendimento aos visitantes parcialmente insustentável.

É necessário destacar que o município de Machadinho-RS não possui unidade de pronto atendimento 24h e o hospital local - Fundação Hospitalar e Educacional São Francisco -, não apresenta equipamentos e estrutura adequada para o funcionamento (Machadinho, 2015). Para questões de maior urgência, tanto residentes quanto visitantes são encaminhados para o Hospital Beneficente São João, no município de Sananduva - RS (Hospital Beneficente São João, 2019), distante $60 \mathrm{Km}$ de Machadinho, que possui maior leque de atendimentos e procedimentos e, em casos mais graves, dirigem-se a Passo Fundo - RS, com distância de 150 Km de Machadinho, para a Associação Hospitalar São Vicente de Paulo, maior instituição hospitalar do interior do estado (Hospital São Vicente de Paulo, 2019).

A partir das informações dos respondentes e das informações secundárias coletadas é possível inferir que a estrutura é suficiente para atender a demanda do dia a dia, porém, em casos graves, de urgência, carece de estrutura para o atendimento tanto dos residentes quanto de visitantes.

\subsubsection{Ensino escolar básico}

No descritor ensino escolar básico, o acesso à educação das crianças e jovens com idade escolar foi considerado por todos os grupos como sustentável. De acordo com dados do IBGE (Ibge, 2017), a taxa de escolarização de crianças e jovens entre 6 e 14 anos de idade é de 98,5\%, ocupando a $207^{\circ}$ posição no estado do RS.

O indicador que reflete a qualidade do ensino básico no município de Machadinho-RS é classificado potencialmente sustentável pelos grupos. O índice de desenvolvimento da educação básica - IDEB - no $3^{\circ}$ ano do ensino médio das escolas públicas no Brasil, alcançado em 2017, é 3,5 enquanto o IDEB do ensino no município é 3,9 (Brasil, 2018). 


\subsubsection{Segurança pública}

Dentre os dois indicadores deste descritor, o primeiro, considerado sustentável, revelou que os residentes sentem-se seguros mesmo com o aumento da demanda em determinadas épocas. Já o indicador que buscou analisar o atendimento da segurança de moradores e visitantes, apresentou-se potencialmente sustentável. Esse dado evidencia que Machadinho-RS é, nesses termos, uma cidade competitiva, frente a outras destinações que oferecem os mesmos segmentos de turismo, porém consideradas inseguras.

O Código de Ética Mundial para o Turismo (Unwto, 2019) destaca que é de responsabilidade das autoridades públicas assegurar a proteção dos visitantes, moradores e prestadores de serviços do setor turístico o que, de acordo com o resultado do indicador, é alcançado pelo município de Machadinho-RS.

\subsubsection{Infraestrutura habitacional}

O indicador que avaliou a existência de meios de transporte para visitação dos atrativos foi considerado potencialmente sustentável. Porém a suficiência do transporte coletivo aos atrativos turísticos apresentou-se de sustentabilidade intermediária para o poder público, comércio, meios de hospedagem e serviços de alimentação, enquanto para os representantes da sociedade civil revelou-se parcialmente insustentável. Cabe ressaltar que PNT 2018-2022 enfatiza que "[...] o planejamento logístico permite aos usuários - turistas - experiências mais ricas, confiáveis e seguras, na medida em que busca otimizar a mobilidade e capacidade de tráfego tanto "no destino" quanto "para o destino". (Brasil, 2015b).

A existência de infraestrutura habitacional em todo município é classificada como potencialmente sustentável, havendo variação moderada entre as respostas. Todavia no indicador dos investimentos de parte da renda do turismo em obras públicas (água, esgoto, eletricidade, pavimentação), os grupos do poder público e sociedade civil apontaram-no como potencialmente sustentável enquanto o comércio, meios de hospedagem e serviços de alimentação conceituam-no insustentável. A partir das informações dos grupos o indicador foi considerado potencialmente sustentável. 


\section{$\underline{\text { 4.2.10 Presença de visitantes }}$}

Entre os grupos, apenas para o poder público, o indicador sobre a presença dos visitantes é considerado parcialmente insustentável, com moderada variação entre as respostas. Os demais grupos apresentam baixa variação das respostas, considerando o indicador sustentável evidenciando que, da forma como o turismo se desenvolve atualmente, os visitantes não são encarados como incômodos ou como responsáveis por impactos negativos na destinação.

É importante salientar que nas comunidades onde o turismo se desenvolve sem a participação da população, os residentes passam a encarar a atividade como invasora de sua realidade e cultura, ao mesmo tempo em que sentem-se excluídas dela (Krippendorf, 2001). Apesar dos indicadores de participação da comunidade contidos no item 2.4 .4 serem, em sua maioria, insustentáveis, nota-se que a população está aberta a receber os visitantes e não tem criado empecilhos para o desenvolvimento da atividade em Machadinho-RS.

\section{$\underline{4.2 .11 \text { Custo de vida }}$}

Enquanto o poder público considera que não houve elevação no custo de vida com o turismo, os demais grupos afirmam que a realidade aponta para um aumento nos preços dos produtos e serviços, reflexo do aumento da demanda, sendo o indicador considerado parcialmente insustentável.

O resultado desse indicador alerta para as possibilidades de aumento da pobreza ou da queda dos níveis sociais da população, caso não haja uma distribuição adequada da renda do turismo. O turista, ao viajar com planejamento, chega na destinação preparado para os preços, possivelmente, maiores que em seus municípios de residência, compreendendo esse fato como consequência do turismo nas destinações. Já os residentes necessitam assimilar e sentir o custobenefício da exploração da atividade turística em seus municípios.

\subsubsection{Análise da sustentabilidade do turismo no município de Machadinho-RS}

De acordo com as investigações os indicadores da dimensão social do turismo do município de Machadinho-RS se encontram em situação sustentável e potencialmente sustentável. Dentre os 28 indicadores da dimensão social três apresentam-se sustentáveis 
(10,72\%), 17 estão potencialmente sustentáveis (60,72\%), quatro de sustentabilidade intermediária $(14,28 \%)$ e os outros quatro parcialmente insustentáveis $(14,28 \%)$.

Dentre os indicadores parcialmente insustentáveis está o que tange a participação da comunidade local, expondo a inexistência ou ineficiência dos projetos sociais voltados a envolver e engajar os residentes no desenvolvimento do turismo local. A partir disso, percebese que os projetos para a melhoria social da população não são suficientes e/ou eficazes, conforme resultado parcialmente insustentável do indicador, demonstrando haver a necessidade de melhorar a qualidade de vida, não apenas por meio financeiro, mas a partir da inserção social. Esses resultados podem estar associados as carências da comunicação turística. Não conhecendo o conceito de sustentabilidade e seus preceitos não há como desenvolver um ambiente sustentável, no qual a comunidade esteja envolvida.

Da mesma forma, outro indicador que merece atenção na dimensão social compreende a divulgação dos atrativos. $\mathrm{O}$ indicador apresenta-se parcialmente insustentável evidenciando que, possivelmente, havendo uma comunicação estratégica, direcionada aos públicos por meio de canais adequados, planejada por profissionais qualificados, o número de visitantes na destinação tende a aumentar. O aperfeiçoamento da comunicação auxiliará, possivelmente, no engajamento dos residentes e o surgimento de novos empreendimentos turísticos. A necessidade de engajar os residentes e criar condições para que eles possam entender o turismo como benéfico para a destinação se dá para que não ocorra um overturism, ou seja, uma rejeição à atividade, como tem ocorrido de forma massiva, principalmente na Europa. Para tanto, os benefícios devem ultrapassar os impactos negativos causados pela atividade (Beni, 2020; Milano et al., 2018).

Há, ainda, quatro indicadores em situação intermediária/neutra. Considerando a inexistência de instituições de ensino técnico e superior no município, a qualificação dos residentes fica prejudicada devido as dificuldades de deslocamento para frequentar aulas sendo, possivelmente, uma das causas de o indicador de qualificação profissional dos residentes apresentar-se intermediário/neutro, bem como o indicador da existência de iniciativas de qualificação. Para transformar essa situação em um ambiente sustentável, cabe a gestão turística local criar parcerias que passem a viabilizar cursos de formação e treinamento para turmas locais, qualificando o atendimento e aumentando o valor do produto turístico.

O outro indicador da dimensão social em situação intermediária/neutra, refere-se ao transporte coletivo para visitação aos atrativos. Sem a existência de meios de transporte 
acessíveis, tanto turistas quanto a população local, em muitos casos, ficam impedidos de conhecer a totalidade do produto turístico local. Além disso, os atrativos e empreendimentos localizados no interior passam a receber poucos visitantes e, como consequência, a atividade turística acaba por se tornar inviável nessas localidades.

O resultado final apresenta um cenário positivo marcado por $71,42 \%$ dos indicadores entre sustentáveis e potencialmente sustentáveis e nenhum indicador insustentável.

\section{Considerações finais}

A partir do desenvolvimento de uma consciência voltada à manutenção dos bens locais, abre-se ao turismo novas possibilidades, envolvendo a comunidade receptora em suas ações e viabilizando a ela melhores condições de vida.

Porém não basta criar planos sustentáveis se não houver análise e monitoramento, contemplando o todo. E são os indicadores os responsáveis por coletar informações para acompanhar o desempenho das ações propostas. A partir dos dados fornecidos pelos indicadores possibilita-se aos gestores turísticos analisar a situação do setor e criar estratégias para melhorias (Nunes \& Martins, 2019; Santos et al., 2020).

Observando esse cenário, o objetivo deste artigo é apresentar os resultados obtidos por meio de uma pesquisa de dissertação, a qual teve como objetivo analisar como se apresenta a sustentabilidade social promovida pelo turismo no parque termal no município de MachadinhoRS. Para alcançar o objetivo proposto, utilizou-se a metodologia do Sistema de Indicadores da Sustentabilidade do Turismo (SISDTur), proposto por Hanai (2009) a partir de adaptações para adequá-lo à realidade do turismo no município de Machadinho-RS.

Ao tratar do objetivo da pesquisa, no ato da aplicação dos questionários aos respondentes, foi possível depreender que o tema "sustentabilidade" não era algo conhecido e/ou entendido pela maioria dos respondentes ou apenas a dimensão ambiental era destacada. A carência percebida na disseminação das dimensões da sustentabilidade induz a comunidade a crença de que apenas o meio ambiente deve ser preservado e explorado de forma racional.

Ainda, apesar de muitos residentes declararem-se favoráveis ao desenvolvimento da atividade turística, não compreendem a pesquisa científica como produtora de informações que, de fato, possibilitem melhorias na realidade local. Pressupõem-se que esse cenário não é uma realidade exclusiva de Machadinho-RS, mas um paradigma presente em grande parte da 
sociedade que não conhece ou não reconhece a relevância das pesquisas científicas relacionadas a temas como o turismo.

Quanto ao objetivo da pesquisa, os resultados apontam para a existência parcial da sustentabilidade social no turismo de Machadinho-RS. A atividade turística tem auxiliado na promoção da qualidade de vida dos residentes, por meio de da abertura de postos de trabalho que possibilitam a qualificação profissional, a aquisição de produtos e serviços, além dos avanços na estrutura física do município, nos serviços básicos como saúde, educação, segurança e crescimento econômico por meio do emprego e da geração e distribuição de renda. Porém, é importante destacar que algumas carências foram descobertas e precisam de ações que viabilizem melhorias. A participação da comunidade local proporcionou um entendimento da situação real, a partir das respostas de quem, de fato, vivencia e constrói o setor turístico no município.

As informações obtidas com esta pesquisa possibilitam um diagnóstico amplo da dimensão social da sustentabilidade do desenvolvimento do turismo de Machadinho - RS, evidenciando que o turismo, quando sustentável, oportuniza a inclusão social e melhorias na qualidade de vida. Por meio dos resultados obtidos, este trabalho propiciou novos conhecimentos acadêmicos no que se refere a compreensão do desenvolvimento sustentável do fenômeno turístico em pequenas cidades. De ordem social, concebeu informações sobre como os residentes veem-se diante das atividades, sentindo-se inseridos ou não, possibilitando a criação de estratégias para engajamento, maior aceitação e participação. Ainda, disponibilizou à gestão turística informações úteis sem que a necessidade de que o governo local tenha que despender gastos com pesquisas realizadas por empresas privadas, direcionando assim, seus esforços e orçamento, para ações de auxílio ao desenvolvimento do empreendedorismo local e melhorias da qualidade de vida dos residentes.

Todavia, ressalta-se a necessidade de novos estudos que abranjam todos as dimensões presentes na metodologia proposta pelo SISDTur e, também, a grande relevância de se investigar informações vindas dos turistas, buscando entender o que os atrai no município e os motivos que os fazem voltar ou indicar a destinação a terceiros. Destaca-se, portanto, que esta é apenas uma parte das explorações que podem e devem ser feitas quanto ao turismo de Machadinho - RS, no intuito de que o ciclo de vida da destinação siga em constante evolução e desenvolvimento, bem como a contribuir para o desenvolvimento de outras destinações turísticas que possam se assemelhar com o município estudado. Novas reflexões possibilitarão 
melhorias e incrementos nos atrativos existentes utilizando todo o potencial de cada recurso, bem como a exploração de novos segmentos do turismo tendo como premissa a sustentabilidade, implementando modelos de desenvolvimento que incluam toda a comunidade.

\section{Referências}

Aguiar, M. F., Bahl, M. (2006). Competência profissional no turismo e compromisso social. Editora ROCA, São Paulo.

Araújo, A. S. (2009). O ciclo de vida do fenômeno turístico em São Lourenço (MG): de estância hidromineral a destino de lazer e bem-estar. Dissertação. Mestrado em Geografia, Universidade Federal de Minas Gerais, Belo Horizonte, MG. Recuperado de: http://www.bibliotecadigital.ufmg.br/dspace/handle/1843/MPBB-7PFLUA. Acesso em 04 abr. 2019.

Ashton, S. M. (2005). O planejamento do turismo: investigação para o desenvolvimento sustentável. Gestão e Desenvolvimento, 2(1), 105-112. Recuperado de: http://periodicos.feevale.br/seer/index.php/revistagestaoedesenvolvimento/article/view/107 0. Acesso em: 05 abr. 2018.

Associação Brasileira de Normas Técnicas. (2016). Nbr 16534: meios de hospedagem indicadores para o sistema de gestão da sustentabilidade. Rio de Janeiro.

Atlas do Desenvolvimento Humano no Brasil. (2019). Machadinho, RS. Recuperado de: http://www.atlasbrasil.org.br/2013/pt/perfil_m/machadinho_rs. Acesso em 13 mar. 2019.

Aurelio Sobrinho, C. (2016). A falácia do desenvolvimento sustentável: uma análise a partir da sociedade de consumo. Tese. Doutorado em Ciências Sociais. Universidade Estadual Paulista, Marília, São Paulo. Recuperado de:

https://repositorio.unesp.br/bitstream/handle/11449/144684/sobrinho_ca_dr_mar.pdf?seque nce=3. Acesso em 20 jan. 2019.

Barretto, M. N. (1991). Planejamento e organização em turismo. Campinas, SP: Papirus. Coleção Turismo.

Beni, M. C. (1999). Análise do desempenho institucional do Turismo na administração pública. In: Castrogiovanni, A. C. \& Gastal, S. (org). Turismourbano: cidades, sites de excitação turística. Porto Alegre: Edição dos Autores.

Beni, M. C. (2006). Política e planejamento estratégico no desenvolvimento sustentável do turismo. Turismo em Análise, 17(1), 5-22.

Beni, M. C. (2020). Saturação e Rejeição ao Turismo nas Destinações Turísticas Turísticas. Revista Brasileira de Pesquisa em Turismo, 14 (2), 1 - 8, maio/ago. Recuperado de: http://dx.doi.org/10.7784/rbtur.v14i2.1847 
Biscaro, M. C. S. (2017). A herança material e imaterial: o legado intocável de Frei Teófilo Antoniazzi a partir de relatos da sua trajetória percorrida no município de Machadinho/RS. Monografia Licenciatura em História. Universidade Federal da Fronteira Sul - UFFS, Campus Erechim.

Brasil. Instituto Nacional de Estudos e Pesquisas Educacionais Anísio Teixeira - INEP. (2018). Índice de desenvolvimento da educação básica - IDEB. Resultados e Metas. Recuperado de: http://ideb.inep.gov.br/. Acesso em 29 maio. 2019.

Brasil. Ministério do Turismo. (2020). Contratada pelo MTur, UnB apresenta proposta de Plano Nacional de Qualificação. 16 de junho de 2020. Recuperado de: http://www.turismo.gov.br/\%C3\%BAltimas-not\%C3\%ADcias/13558-contratada-pelomtur,-rede-de-institui\% $3 \% \mathrm{~A} 7 \% \mathrm{C} 3 \% \mathrm{~B} 5$ es-apresenta-proposta-deimplanta\%C3\%A7\%C3\%A3o-do-plano-nacional-de-qualifica\%C3\%A7\%C3\%A3o-noturismo.html.

Brasil. Ministério do Trabalho e Emprego. (2019c). RAIS vinculo. Recuperado de: http://bi.mte.gov.br/bgcaged/rais.php. Acesso em 13 mar. 2019.

Brasil. Ministério do Turismo. (2015a). Diretrizes nacionais para qualificação em turismo. Recuperado de: http://www.turismo.gov.br/images/pdf/DNQT_Diretrizes_Nacionais_Qualificacao_03_03_ 2015.pdf. Acesso em: 10 abr. 2018.

Brasil. Ministério do Turismo. (2015b). Plano nacional de turismo 2018-2022: mais emprego e renda para o brasil. Brasília: Mtur. Recuperado de: http://www.turismo.gov.br/2015-0309-13-54-27.html. Acesso em 02 maio 2019.

Bushell, R. \& Sheldon, P. J. (eds). (2009). Wellness and tourism: mind, body, spirit, place. Elmsford, NY: Cognizant Communication.

Butler, R. W. (1999). Sustainable tourism - a state of art review. Tourism Geographies, 1, 725.

Campos, A. C., Mendes, J. C. \& Silva J. A. (2006). Para uma cultura da qualidade total no destino turístico: métodos de diagnóstico e estratégias de desenvolvimento. Revista Turismo e Desenvolvimento, 5, p. 21-40. Recuperado de: http://www.ua.pt/degeit/rtd/indice5. Acesso em 28 jan. 2019.

Cervo, A.L. \& Bervian P. A. (2002). Metodologia científica. 5 ed. São Paulo: Prentice Hall.

Costa, N. D., Melo, A. S. \& Pimenta, M. L. P. (2017). Turismo e trabalho em pequenas cidades. Rosa dos Ventos, 9(II), 228-244. Recuperado de: http://www.ucs.br/etc/revistas/index.php/rosadosventos/article/view/4669/pdf. Acesso em: 28 jan. 2019.

Dencker, A. F. M. (Org.) (2004). Planejamento e gestão de hospitalidade e turismo: formulação de uma proposta. São Paulo: Pioneira Thomson Learning. 
Dempsey, N., Bramley, G. Power, S \& Brown, C. (2011). The social dimension of sustainable development: defining urban social sustainability, Sustainable Development, 19, 289-300.

Dias, R. (2008). Sociologia do Turismo. São Paulo: Atlas, 2008.

Dorin, B. (2013). Sustainable tourism and its forms - a theoretical approach. Annals of Faculty of Economics, 1(1), 759-767. Recuperado de: https://ideas.repec.org/a/ora/journl/v1y2013i1p759-767.html. Acesso: em 16 abr. 2018.

Ferreira, J. C., Bertonili G. R. F. \& Brandalise L. T. (2019). Análise do nível de sustentabilidade da rede hoteleira de Foz do Iguaçu - PR. Tur., Visão e Ação, 21(2), 102127, Mai./Ago. DOI: 10.14210/rtva.v21n2.p102-127

Fonseca, J. J. S. (2002). Metodologia da pesquisa científica. Fortaleza: UEC.

Gil, A. C. (2002). Como elaborar projetos de pesquisa. 4 ed. São Paulo: Atlas.

Goeldner, C. R., Ritchie, J. R. B. \& Mcintosh, R. W. (2002). Turismo: princípios, práticas e filosofias. Tradução Roberto Cataldo Costa. 8 ed. Porto Alegre: Bookman.

Hanai, F. Y. (2009). Sistema de indicadores de sustentabilidade: uma aplicação ao contexto de desenvolvimento do turismo na região de Bueno Brandão, Estado de Minas Gerais, Brasil. Tese de Doutorado em Ciências da Engenharia Ambiental - Universidade de São Paulo - USP, São Carlos. Recuperado de: http://www.teses.usp.br/teses/disponiveis/18/18139/tde-17092009-082223/pt-br.php. Acesso: em 15 abr. 2018.

Hospital Beneficente São João. (2019). Institucional. Recuperado de: http://hbsj.com.br/historico-hospital-beneficiente-sao-joao/. Acesso em 02 maio. 2019.

Hospital São Vicente De Paulo. (2019). Quem somos. Recuperado de: https://www.hsvp.com.br/hospital/16/QuemSomos.html. Acesso em 02 maio 2019.

Ibge. (2017). Cidades. Recuperado de: https://cidades.ibge.gov.br/brasil/rs/machadinho/historico. Acesso em 22 abr. 2018.

Irving, M. A., Bursztyn, I., Sancho, A. P. \& Melo, G. M. (2005). Revisitando significados em sustentabilidade no planejamento turístico. Caderno Virtual de Turismo, 18,1-7. Recuperado de: http://www.ivt.coppe.ufrj.br/caderno/index.php/caderno/article/view/98. Acesso em: 02 mai. 2019.

Jegdić, V., Škrbić, I. \& Milošević, S. (2013). Specifičnosti planiranja održivog turizma. TIMS Acta, 7, 153-162. Recuperado de: https://doaj.org/article/09752e211f9a4a32a721dc431dd6e331. Acesso em: 15 abr. 2018.

Jorge, M. J. F. (2015). A cultura da sustentabilidade social, um instrumento de humanização. Dissertação de Ciências Jurídico-Forenses. Universidade de Coimbra, Coimbra, Portugal. 
Ko, T.G. (2005). Development of a tourism sustainability assessment procedure: a conceptual approach. Tourism Management, 26(3), 431-445. Recuperado de: https://www.sciencedirect.com/science/article/pii/S026151770400041X. Acesso em 02 mai. 2019.

Krippendorf, J. (2001). Sociologia do turismo - para uma nova compreensão do lazer e das viagens. São Paulo: Aleph.

Lage, B. . HG \& Milone, P. C. (1998). Economia do turismo. São Paulo: Papirus.

Lacerda, L. T \& Mecca, M. S. M. (2018). Turismo Termal: um estudo bibliométrico. XVSeminário da Associação Nacional de Pesquisa e Pós-Graduação em Turismo19 a 21de setembro de 2018-São Paulo/SP. Recuperado de: https://www.anptur.org.br/anais/anais/files/15/1069.pdf.

Lemos, L. (2005). O valor turístico na economia da sustentabilidade. São Paulo: Aleph.

Likert, R. (1932). A technique for measurement of attitudes. Archives of Psychology, 140, 555.

Lin, D., \& Simmons, D. (2017). Structured inter-network collaboration: public participation in tourism planning in Southern China. Tourism Management, 63, 315-328.

Machadinho. Prefeitura de Machadinho. (2015). Administrador da Fundação Hospitalar São Francisco comenta atual situação do hospital em Machadinho. 22 julh. 2015. Recuperado de: http://www.machadinho.rs.gov.br/noticia/48/22-07-2015/administrador-da-fundacaohospitalar-sao-francisco-comenta-atual-situacao-do-hospital-em-machadinho. Acesso em 01 mai. 2019.

Milano, C., Cheer, J. M. \& Novelli M. (2018). Overtourism is becoming a major issue for cities across the globe. Word Economy Forum. Reuperado de: https://www.weforum.org/agenda/2018/07/overtourism-a-growing-global-problem.

Moleiro, D. F. (2020). Urban tourism planning for sustainability - A literature review. Research, Society and Development, 9(8) e338985561. Recuperado de: https://rsdjournal.org/index.php/rsd/article/view/5561.

Molina, S. (1997). Turismo: Metodologia para su planificación. México: Trillas.

Muniz, S. R. (2015). Fundamentos da matemática II. São Paulo: USP.

Naraindas, H. \& Bastos, C. (2011). Healing holidays? Itinerant patients, therapeutic locales and the quest for health. Anthropology and Medicine, 8(1), 1-6. Recuperado de: https://www.tandfonline.com/doi/pdf/10.1080/13648470.2010.525871 ?needAccess=tru. Acesso em 08 abr. 2019. 
Novaes, M. H. (2013). Análise da gestão ambiental dos meios de hospedagem no espaço rural da região serrana de Santa Catarina. Tese de Doutorado Administração e Turismo. Universidade do Vale do Itajaí, Biguaçu, Santa Catarina.

Nugraheni, A. I. P., Priyambodo, T. K., Sutikno, B., \& Kusworo, H. A. (2020). The Social Dimensions' Aspects of Sustainable Tourism Development Analysis: A Systematic Literature Review. Digital Press Social Sciences and Humanities, 4, 00001. DOI: 10.29037/digitalpress.44348

Nugraheni, A. I. P., Priyambodo, T. K., Kusworo, H. A., \& Sutikno, B. (2019). The social dimension of sustainable development: defining tourism social sustainability. Proceeding of the 1st International Conference on Engineering, 18-19. Labuan Bajo, Nusa Tenggara Timur, Indonesia, Oktober 2019.

Nunes, E. R. \& Martins, M. F. (2019). Indicadores de sustentabilidade para o turismo sustentável: um estudono município de Bananeiras (PB). Revista Brasileira de Ecoturismo, 12(2), 258-273.

Oliveira, C. G. S. (2002). Viabilidade e sustentabilidade do turismo rural. Brasília, DF: Serviço Nacionalde Aprendizagem do Cooperativismo.

Powis, B. \& O'leary, Z. (2009). Wellness tourism and health promotion. Healthy tourists and environments. In: Bushell, R. \& Sheldon, P. J. (Ed.). Wellness and tourism: mind, body, spirit, place. Elmsford, NY: Cognizant Communication, p. 52-68.

Prescott-Allen, R. (2001). The wellbeing of nations: A country-bycountry index of quality of life and the environment. Washington, DC: Island Press.

Quintela, J., Correia, A. \& Antunes, J. (2011). Service quality in health and wellness tourism trends in Portugal. International Journal of Business, 2(3), 1-8. Recuperado de: https://www.researchgate.net/publication/228962910_Service_quality_in_health_and_well ness_tourism-trends_in_Portugal. Acesso em 05 abr. 2019.

Quintela, J., Costa, C. \& Correia, A. (2017). The role of health and wellness tourism in sustainable territorial development. Tourism and Hospitality Journal, 9(2), 113-121. Recuperado de: https://comum.rcaap.pt/handle/10400.26/22836. Acesso em 01 abr. 2019.

Quintela, M. M. (2004). Saberes e práticas termais: uma perspectiva comparada em Portugal (Termas de S. Pedro do Sul) e no Brasil (Caldas da Imperatriz). História, Ciências, Saúde, 11(supl 1), 239-60. Recuperado de: http://www.scielo.br/pdf/hcsm/v11s1/11.pdf. Acesso em: 12 dez. 2017.

Ranauro, M. L. (2004). Sustentabilidade numa perspectiva endógena: contribuição das "comunidades" no plano simbólico do desenvolvimento sustentável. Caderno Virtual de Turismo, 4(14), 21-28. Recuperado de: http://www.ivt.coppe.ufrj.br/caderno/index.php/caderno/article/view/67. Acesso em 02 maio 2018. 
Rejowski, M., Yasoshima, J. R., Stigliano, B. V. \& Silveira, A. S. (2002). Desenvolvimento do turismo moderno. In: Rejowski, M, (org). Turismo no percurso do tempo. São Paulo: Aleph, p. 42-70.

Renk, V. E. (2013). Turismo e cultura: um diálogo interdisciplinar. Caderno de Estudos e Pesquisas do Turismo, 2, 63-79. Recuperado de:

http://www2.pucpr.br/reol/pb/index.php/turismo?dd99=issue\&dd0=533. Acesso em: 23 abr. 2018.

Rio Grande Do Sul. Secretaria da Cultura, Turismo, Esporte e Lazer. (2019). Thermas Machadinho. Recuperado de: http://www.turismo.rs.gov.br/atrativo/2517/thermasmachadinho.

Rigsby, L. (1987). Delineamento de pesquisa de levantamento. In: Kidder, L. H. (org). Métodos de pesquisa nas relações sociais: Selltiz, Wrightsman e Cook. 2 ed. São Paulo: EPU.

Rocha, A. S. S. (2011). Análise à oferta termal nacional. Dissertação de Mestrado em Gestão e Economia dos Serviços de Saúde. Faculdade de Economia da Universidade do Porto, Portugal. Recuperado de: https://repositorio-aberto.up.pt/handle/10216/57180. Acesso em: 15 abr 2018.

Ruschmann, D. V. M. (2000). Turismo e planejamento sustentável: a proteção do meio ambiente. 6 ed. Campinas, SP: Papirus.

Sachs, I. (2007). Rumo à ecossocioeconomia: Teoria e prática do desenvolvimento. São Paulo: Cortez, 2007.

Santos, J. G. (2013). Sistema de indicadores de sustentabilidade para o turismo: aplicação de uma abordagem participativa em Porto de Galinhas/PE. Dissertação de Mestrado em Administração - Universidade Federal de Pernambuco, PE.

Santos, M., Costa, P. F. \& Santos, E. C. O. (2020). Aplicação de indicadores do turismo sustentável em um balneário em área de cerrado no município de Coxim - MS. Holos Environment, 20 (3): 442-457. Recuperado de: https://www.ceaunesp.org.br/holos/article/view/12380.

Sassaki, R. K. (2009). Inclusão: acessibilidade no lazer, trabalho e educação. Revista Nacional de Reabilitação (Reação), 7, 10-16.

Smith, M. K. \& Puczkó, L. (2017). Balneology and health tourism. In: Smith, MK \& Puczkó, L (ed.). The Routledge handbook of health tourism, Abingdon: Routledge, p. 271-282.

Souza, A. C., Fialho, F. A. P. \& Otani, N. (2007). TCC: métodos e técnicas. Florianópolis: Visual Books.

Souza, J. L. (2008). O que é? IDH. Instituto de Pesquisa Econômica Aplicada - Ipea. Ano 5, ed. 39. Recuperado de: 
http://www.ipea.gov.br/desafios/index.php?option=com_content $\&$ view $=$ article $\&$ id=2144:c atid=28\&Itemid=23. Acesso em 23 mar. 2019.

Stevens, F., Azara, I. \& Michopoulou, E. (2018). Local community attitudes and perceptions towards thermalism. International Journal of Spa and Wellness, 1(1), 55-68. Recuperado de: https://www.tandfonline.com/doi/full/10.1080/24721735.2018.1432451. Acesso em 01 abr. 2019.

Stevenson, Wj. (1981). Estatística aplicada à administração. São Paulo: Habra.

Teixeira, F., Vieira, F., \& Mayr, L. (2019). Turismo de base comunitária: uma abordagem na perspectiva da análise de clusters. Turismo - Visão e Ação, 21(2), 02-21.

Tolkes, C. (2018). Sustainability communication in tourism - A literature review. Tourism Management Perspectives 27 (2018), 10-21.

Unwto. (2019). Global Code of Ethics for Tourism. Recuperado de: http://ethics.unwto.org/en/content/global-code-ethics-tourism. Acesso em 03 maio. 2018.

UNWTO. Guia de desenvolvimento do turismo sustentável. Tradução de Sandra Netz. Porto Alegre: Bookman, 2003.

Unwto. (2005). Indicadores de desarrollo para los destinos turísticos: Guia Prático. Madrid: OMT.

Unwto, United Nations Global Compact Network Spain. (2016). The tourism sector and the sustainable development goals - responsible tourism, a global commitment. Recuperado de: http://cf.cdn.unwto.org/sites/all/files/pdf/turismo_responsable_omt_acc.pdf. Acesso em: 21 abr. 2018.

Vianna, S. L. G. (2011). A competitividade e a qualidade de vida nas destinações turísticas: análise quanto à sua correspondência. Tese de Doutorado em Administração e Turismo Universidade do Vale do Itajaí, Itajaí, SC. Recuperado de: http://siaibib01.univali.br/pdf/silvio\%20luiz\%20goncalves\%20vianna.pdf. Acesso em: 04 abr. 2018. 


\section{ANEXO - INSTRUMENTO DE COLETA DE DADOS}

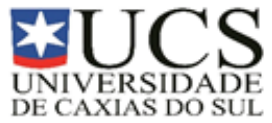

Programa de Pós-Graduação em Turismo e Hospitalidade - Mestrado

Este questionário destina-se a contribuir com a pesquisa da mestranda Luana Teixeira de Lacerda, aluna do curso de Pós-Graduação em Turismo e Hospitalidade da Universidade de Caxias do Sul.

A colaboração na pesquisa não resultará em remuneração ou benefício pessoal de qualquer ordem. Os resultados advindos desta pesquisa poderão possibilitar o desenvolvimento científico na área, sendo passivel a publicação em textos acadêmicos (periódicos científicos, congressos e eventos similares).

\section{Observações gerais:}

- A confidencialidade sobre os respondentes será mantida em todo o trabalho, somente serão divulgados nomes, caso o pesquisado autorize tal divulgação;

- O questionário está dividido entre a caracterização do perfil do pesquisado e os aspectos relacionados a dimensão social e à dimensão econômica da sustentabilidade turística de Machadinho, RS.

- Escolha apenas uma resposta para cada item;

- Cada dimensão apresenta vários indicadores, que são apresentados como afirmativas que devem ser ponderadas de acordo com os niveis apresentados a seguir:

\begin{tabular}{|l|l|l|}
\hline Nivel & Ponderação & Descrição \\
\hline 1 & Discordo Totalmente & $\begin{array}{l}\text { Você não apresenta NENHUMA concordância com o que foi } \\
\text { afirmado. }\end{array}$ \\
\hline 2 & Discordo Parcialmente & $\begin{array}{l}\text { Você apresenta ALGUMA discordância com o que foi } \\
\text { afirmado. }\end{array}$ \\
\hline 3 & Neutro & $\begin{array}{l}\text { Você não discorda, mas TAMBEM não concorda com tal } \\
\text { afirmação. }\end{array}$ \\
\hline 5 & Concordo Parcialmente & $\begin{array}{l}\text { Você apresenta ALGUMA concordância com } \circ \text { que foi } \\
\text { afirmado. }\end{array}$ \\
\hline
\end{tabular}

PERFIL SOCIAL

Gênero: () Feminino () Masculino

Ano de nascimento:

Naturalidade:

Mora em Machadinho há quanto tempo?

Ramo de atividade: () Comércio () Hospedagem ( ) Alimentação ( ) Poder Público ( ) Outra. Qual?

Grau de escolaridade:

(a) Ensino fundamental incompleto ( $4^{\circ}$ série) () Ensino fundamental ( $8^{\circ}$ série)

(f) Ensino Médio () Ensino Superior ( ) Pós-Graduação

Renda individual bruta mensal:

(n) Até R\$ 954,00

(1) Entre R\$ 954,01 e RS 1.908

(n) Entre R\$ 1.908 e R\$2.862,01

(1) Entre R\$ $2.862,01$ e RS $4.770,01 \mathrm{e}$

(a) Mais de $R \$ 4.770,01$

Para responder as questões considere a seguinte escala, optando por apenas uma alternativa:

Discordo totalmente; 2. Discordo parcialmente; 3. Nem Concordo/Nem Discordo - Neutro; 4.

Concordo parcialmente; $\mathbf{5}$. Concordo totalmente. 


\begin{tabular}{|c|c|c|c|c|c|c|}
\hline \multicolumn{7}{|c|}{ Dimensảo Social } \\
\hline & & \begin{tabular}{|l|}
1 \\
Discordo \\
totalmente \\
\end{tabular} & \begin{tabular}{|l|}
2 \\
Discordo \\
parcialmente
\end{tabular} & Neutro & $\begin{array}{l}{ }^{4} \text { Concordo } \\
\text { parcialmente }\end{array}$ & \begin{tabular}{|l|}
5 \\
Concordo \\
totalmente
\end{tabular} \\
\hline 1. & $\begin{array}{l}\text { Hi um percentual significativo de residentes } \\
\text { locais empregados nos estabelecimentos do } \\
\text { destino turistico (considerando que o número } \\
\text { total de empregos formais \& } 794 \text { vagas, } \\
\text { enquanto que empregos no setor de comerecio } \\
\text { e serviços somam } 414 \text { vagas (CNAE, 2018). }\end{array}$ & & & & & \\
\hline 2. & A maioria dos funcionánios é de origem local. & & & & & \\
\hline 3. & $\begin{array}{l}\text { Ha vagas de emprego inclusivas (para todas } \\
\text { as pessoas independente de etnia, raça, } \\
\text { lingua, nacionalidade, gênero, orientação } \\
\text { sexual, deficiencia e outros atributos) em } \\
\text { atividades turisticas. }\end{array}$ & & & & & \\
\hline 4. & $\begin{array}{l}\text { Dentre proprietánios e empresánios turisticos, } \\
\text { a maionia e de origem local }\end{array}$ & & & & & \\
\hline 5. & $\begin{array}{l}\text { Existem iniciativas de capacitaç̧o e } \\
\text { treinamento profissional para os residentes } \\
\text { locais (por parte da gestäo pública e privada). }\end{array}$ & & & & & \\
\hline 6. & $\begin{array}{l}\text { Dentre of fumcionários que sejam residentes } \\
\text { locais há uma parcela com capacitaçấo em } \\
\text { turismo. }\end{array}$ & & & & & \\
\hline 7. & $\begin{array}{l}\text { O número de empregos fixos em turismo é } \\
\text { maior que o numero de empregos } \\
\text { temporários no setor. }\end{array}$ & & & & & \\
\hline 8. & $\begin{array}{l}\text { Os moradores obtèm com facilidade as } \\
\text { informaç̄es sobre as atividades turisticas. }\end{array}$ & & & & & \\
\hline 9. & $\begin{array}{l}\text { A divulgaçāo dos atrativos turistico do } \\
\text { municipio é suficiente para atrair visitantes. }\end{array}$ & & & & & \\
\hline 10. & $\begin{array}{l}\text { Existem locais onde os turistas podem obter } \\
\text { informaçoes básicas sobre turismo e } \\
\text { infraestrutura local. }\end{array}$ & & & & & \\
\hline 11 & $\begin{array}{l}\text { Existem iniciativas de comumicaçăo a } \\
\text { respeito da sustentabilidade oconómica e e } \\
\text { social da atividade turistica local. }\end{array}$ & & & & & \\
\hline 12. & $\begin{array}{l}\text { Existem programas eou projetos sociais que } \\
\text { envolvam os residentes locais visando } \\
\text { engaiá-los no desenvolvimento do turismo. }\end{array}$ & & & & & \\
\hline 13. & $\begin{array}{l}\text { Residentes ifuncionários de } \\
\text { estabelecimentos possuem informacôes } \\
\text { basicas para esclarecer os turistas. }\end{array}$ & & & & & \\
\hline 14. & $\begin{array}{l}\text { Existem programas e ou projetos voltados ás } \\
\text { melhorias sociais dos residentes. }\end{array}$ & & & & & \\
\hline 15 & $\begin{array}{l}\text { Existem projetos voltados à sustentabilidade } \\
\text { económica e social do turismo local. }\end{array}$ & & & & & \\
\hline 16. & $\begin{array}{l}\text { Os serviços básicos de saúde săo suficientes } \\
\text { para atender a população local. }\end{array}$ & & & & & \\
\hline 17. & $\begin{array}{l}\text { A estrutura dos serviços básicos de saúde é } \\
\text { suficiente para atender as necessidades dos } \\
\text { visitantes. }\end{array}$ & & & & & \\
\hline 18. & $\begin{array}{l}\text { Todas as crianças e jovent com idade escolar } \\
\text { têm acesso ḋ educaçấo. }\end{array}$ & & & & & \\
\hline 19. & $\begin{array}{l}\text { A qualidade do ensino básico local é } \\
\text { satisfatória (considerando que o indice de } \\
\text { desenvolvimento da educaçẫo básica - IDEB }\end{array}$ & & & & & \\
\hline & $\begin{array}{l}\text { no } 3^{\circ} \text { ano do ensino médio das escolas } \\
\text { públicas no Brasil, alcancado em 2017, é 3,5 } \\
\text { eo o IDEB local ê 3,9) (BRASIL, 2018), } \\
\end{array}$ & & & & & \\
\hline 200 & $\begin{array}{l}\text { Os residentes sentem-se seguros ao transitar } \\
\text { pelo municipio. }\end{array}$ & & & & & \\
\hline 2 & $\begin{array}{l}\text { A segurança pública é satisfatória para } \\
\text { atender residentes e turistas. }\end{array}$ & & & & & \\
\hline 22 & $\begin{array}{l}\text { Existe infraestrutura habitacional (agua, } \\
\text { esgoto, eletricidade, pavimentaça)o) em todo } \\
\text { municipio. }\end{array}$ & & & & & \\
\hline 23 & $\begin{array}{l}\text { O transporte coletivo é sufieiente para } \\
\text { atender a demanda. }\end{array}$ & & & & & \\
\hline 24. & $\begin{array}{l}\text { Há transporte coletivo para a visitaçảo dos } \\
\text { atrativos turisticos. }\end{array}$ & & & & & \\
\hline 25 & $\begin{array}{l}\text { O turismo proporcionou melhorias na } \\
\text { qualidade estrutural do municipio. }\end{array}$ & & & & & \\
\hline 26. & $\begin{array}{l}\text { A presença dos visitantes nío causa } \\
\text { desconforto aos residentes. }\end{array}$ & & & & & \\
\hline 27 & $\begin{array}{l}\text { Não houve elevaçăo no custo de vida dos } \\
\text { moradores após o início da exploraçăo do } \\
\text { turismo local (com a abertura do Themas } \\
\text { Machadinha). }\end{array}$ & & & & & \\
\hline
\end{tabular}

